\title{
Moisture ingress in cracked cementitious materials
}

Michel, Alexander; Pease, B.J.

Published in:

Cement and Concrete Research

Link to article, DOI:

10.1016/j.cemconres.2018.08.009

Publication date:

2018

Document Version

Peer reviewed version

Link back to DTU Orbit

Citation $(A P A)$ :

Michel, A., \& Pease, B. J. (2018). Moisture ingress in cracked cementitious materials. Cement and Concrete Research, 113, 154-168. https://doi.org/10.1016/j.cemconres.2018.08.009

\section{General rights}

Copyright and moral rights for the publications made accessible in the public portal are retained by the authors and/or other copyright owners and it is a condition of accessing publications that users recognise and abide by the legal requirements associated with these rights.

- Users may download and print one copy of any publication from the public portal for the purpose of private study or research.

- You may not further distribute the material or use it for any profit-making activity or commercial gain

- You may freely distribute the URL identifying the publication in the public portal

If you believe that this document breaches copyright please contact us providing details, and we will remove access to the work immediately and investigate your claim 


\title{
Moisture ingress in cracked cementitious materials
}

\author{
A. Michel ${ }^{\text {a }}$ \& B.J. Pease ${ }^{b}$ \\ a) Technical University of Denmark (DTU), Department of Civil Engineering, Kgs. Lyngby, Denmark \\ +45 4525 1656, +45 4588 3282, almic@byg.dtu.dk, http://www.dtu.dk \\ b) COWI A/S Denmark, Kongens Lyngby, Denmark \\ +454176 0191, brpe@cowi.com
}

\begin{abstract}
Wedge split test specimens were conditioned to a relative humidity of $50 \%$, deformed to various damage states, and exposed to liquid water. Water ingress was monitored using x-ray attenuation measurements and compared to numerical predictions. The transport model accounts for the damage state using the cracked hinge model and a simplified approach whereby a crack is considered to consist of two distinct parts: 1) a coalesced crack behaving as a free surface for moisture ingress, and 2) an area of isolated micro cracks behaving as bulk material. Comparison of experimental and model results shows the simplified crack geometry approach applied in the transport model is capable of predicting the ingress of moisture and influence of cracks. The model was found to underestimate the vertical extent of moisture ingress in the largest CMOD samples $(0.20$ and $0.40 \mathrm{~mm})$, which was likely due to instability of the large cracks in these samples.
\end{abstract}

Keywords: X-ray attenuation measurement technique, B. Microcracking, C. Transport Properties, E. Modelling 


\section{Introduction}

The state and distribution of moisture in (reinforced) cementitious materials is of great importance for the assessment and prediction of many deterioration mechanisms, such as reinforcement corrosion, alkali silica reaction, carbonation, freeze thaw, etc., see e.g. [1-4] Thus, the prediction of the moisture distribution as a result of the interaction of cementitious materials with the environment, i.e. moisture ingress, has been subject of numerous experimental and numerical studies, see e.g. [5-7]. While research on the governing transport phenomena related to moisture ingress, such as diffusion, permeability, capillary suction, has received a great deal of attention, see e.g. [8-10], the impact of cracks on the moisture ingress in cementitious materials is studied to a far less extent. In practice, however, cracks can be found in nearly all reinforced concrete structures originating, among others, from hygral or thermal shrinkage and/or mechanical loading. Nevertheless, studies concerning the impact of cracks on moisture ingress in cementitious materials have generally concluded that cracks facilitate rapid ingress of moisture as well as aggressive substances, such as chlorides, carbon dioxide, etc., [11-17] and subsequently may reduce the service life of reinforced concrete structures.

To enable realistic predictions of the moisture ingress in cementitious materials, numerical tools need to be tested against and calibrated with experimental data. Experimental investigations and data must thereby concern both the spatial resolution of moisture ingress and a realistic representation of the crack morphology, in cases where moisture ingress in cracked materials is studied. While several studies have demonstrated that various techniques are applicable to obtain desired spatial resolution for moisture ingress, limited studies conducted experimental investigations to determine the moisture ingress in cementitious materials with realistic crack morphologies. Commonly, artificial cracks are introduced to study the moisture ingress by means of sawing or casting, see e.g. [13]. While such studies may be used to represent idealized cases for numerical simulations, the predictive capabilities of such approaches may be limited for actual structures.

The focus of this study was to provide experimental data of moisture ingress in cementitious materials with load-induced crack morphologies. The impact of loading and cracking on the moisture ingress was investigated for steel fibre reinforced concrete $(0.25 \%$ fiber by volume) subjected to the wedge splitting test. Before exposure to moisture, test specimens were loaded or cracked to desired load levels and crack widths, respectively, and conditioned at a relative humidity of $50 \%$ for one year. Upon conditioning, the test specimens were exposed to liquid water and the moisture ingress monitored by means of repeated x-ray attenuation measurements over a period of 24 hours. In addition to the experimental investigations, predictions of a numerical model are presented in this study. The model is based on a liquid conductivity approach and accounts for the impact of cracks by means of a simplified crack geometry to predict the moisture ingress in cementitious materials. Although, the concept of moisture ingress through a simplified crack geometry is demonstrated in this study for steel fibre reinforced concrete, it can be expected that the approach is also valid for cementitious materials without (steel) fibre reinforcement, when crack width and length are determined by fracture mechanical approaches. The analysis of crack propagation in reinforced concrete, at a structural level, is commonly performed by means of cohesive crack models [18]. Although these models only provide limited information on width and length of cracks, integration of moisture ingress and simplified crack geometries presents a considerable step forward in state-of-the-art service life predictions for reinforced concrete structures. Within the modelling approach, the crack is thereby divided into two distinct 
regions: $i$ ) a coalesced crack region, which behaved as a free surface for moisture ingress and $i$ ) a noncoalesced crack region, for which similar transport properties as for the bulk material are assigned.

\section{Experimental investigations}

To investigate the impact of cracks on the moisture transport in cementitious materials, wedge split test (WST) specimens were prepared, conditioned, cracked, and exposed to liquid water. Experimental investigations covered mechanical testing and non-destructive x-ray attenuation measurements.

Mechanical testing consisted of a splitting load applied to WST specimens via a rigid wedge using crack mouth opening displacement (CMOD) control. Initially, three samples were cracked to a CMOD of $1.8 \mathrm{~mm}$, to allow for the estimation of materials properties using the cracked hinge model (CHM) as described in Section 2.3, while the remaining samples were loaded or cracked to $70 \%$ and $90 \%$ of peak load, peak load, $0.10 \mathrm{~mm}, 0.15 \mathrm{~mm}, 0.20 \mathrm{~mm}$, and $0.40 \mathrm{~mm}$ CMOD. After loading/cracking of the WST specimens, aluminum tape was used to seal all specimen sides except the top surface, which provided a pond for exposure to liquid water via the cast-in recess and cut notch. The CMOD was measured directly above the cut notch, at the bottom of the specimen's recess.

In addition to the mechanical testing, non-destructive x-ray attenuation measurements were undertaken to determine the moisture content in the loaded or cracked WST specimens during ponding with liquid water. A $25 \times 25 \mathrm{~mm}^{2} \mathrm{x}$-ray camera captured repeatedly images of 15 locations, providing data from an $80 \times 55 \mathrm{~mm}^{2}$ region of the WST specimens. The measured region was centered horizontally with the notch and vertically the measurement area started approximately $10 \mathrm{~mm}$ above the specimen bottom. Figure 1 illustrates both the cross section of the WST specimen and approximate locations where x-ray camera images were captures.

For convenience, the specimen identifications used throughout are based on the CMOD or load condition associated with each specimen. It is however important to note that the actual crack widths affecting the ingress of water are smaller than the CMOD due to the tapered nature of cracks formed in the WST specimen (this is discussed in detail in Section 4 and Table 3).

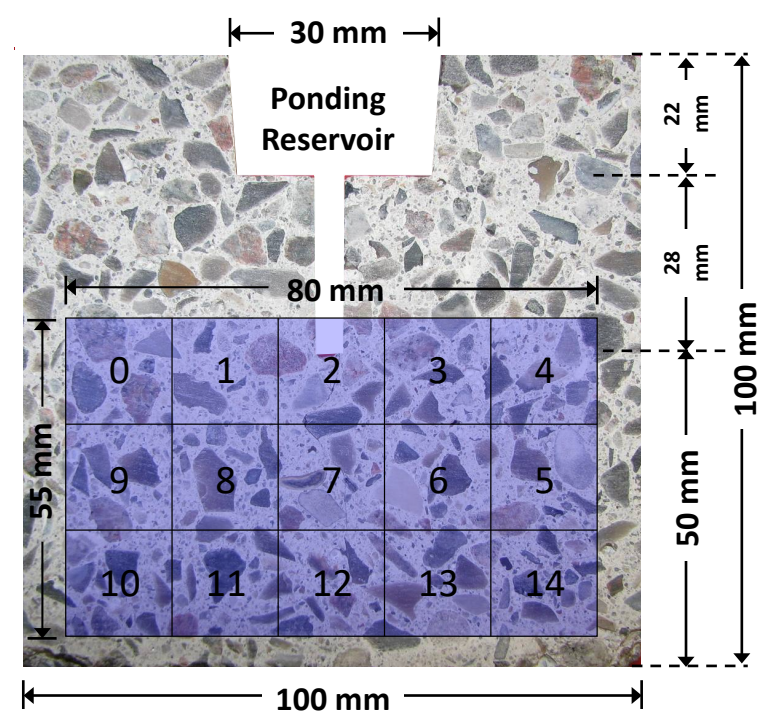

Figure 1: The WST specimen geometry and details on location of x-ray images. Please note: not to scale. 


\subsection{Materials and specimen preparation}

Aalborg White ${ }^{\circledR}$ Portland cement was used to prepare the WST specimens and had an estimated Bogue composition of $78.8 \% \mathrm{C}_{3} \mathrm{~S}, 10.5 \% \mathrm{C}_{2} \mathrm{~S}, 4.9 \% \mathrm{C}_{3} \mathrm{~A}, 1.0 \% \mathrm{C}_{4} \mathrm{AF}, 0.6 \% \mathrm{MgO}, 2.1 \% \mathrm{SO}_{3}$, and a $\mathrm{Na}_{2} \mathrm{O}$ equivalent alkali content of $0.19 \%$. Aggregates used were washed Class E 0-4 mm sea-sand and Class A 4-8 $\mathrm{mm}$ sea-gravel (in accordance with [19]). The water-to-cement ratio was 0.50 with a cement content of $330 \mathrm{~kg} / \mathrm{m}^{3}, 764 \mathrm{~kg} / \mathrm{m}^{3}$ fine aggregates, $1,099 \mathrm{~kg} / \mathrm{m}^{3}$ coarse aggregates $(71.5 \%$ aggregate by volume), and $19 \mathrm{~kg} / \mathrm{m}^{3}$ steel fibers ( $0.25 \%$ fiber by volume). The steel fibers had a length of $12.5 \mathrm{~mm}$, diameter of $0.4 \mathrm{~mm}$, elastic modulus of $200 \mathrm{GPa}$, and tensile strength of $1300 \mathrm{MPa}$. The concrete was mixed using a standard pan mixer with a 1201 capacity. The fine and coarse aggregate were first mixed dry for $1 \mathrm{~min}$, followed by $3 \mathrm{~min}$ mixing with one third of the mixing water. Mixing was stopped for 2 min prior to adding and mixing the cement for $1 \mathrm{~min}$. The remaining water was then added and mixing continued for 3 min after addition of water, during which time the steel fibers were added. The mixer was then opened and the pan and blades were scraped, followed by 1 min additional mixing. Upon mixing, concrete was placed and compacted by combined rodding and vibration in customized wedge split test (WST) specimen molds yielding a $100 \times 100 \times 100 \mathrm{~mm}^{3}$ prism with a recess on the specimen's top; as shown in Figure 1. After casting, specimens were stored in laboratory conditions (i.e., $18 \pm 2$ ${ }^{\circ} \mathrm{C}$ ) covered with wet burlap and plastic sheets for 24 hours. Subsequently, the specimens were sealed in multiple layers of plastic at $20 \pm 2{ }^{\circ} \mathrm{C}$ and cured for another 6 days before placing the still sealed samples in an oven at $45 \pm 2{ }^{\circ} \mathrm{C}$ until samples reached a maturity age of 1 year. After accelerated curing, specimens were unsealed, a $28 \mathrm{~mm}$ notch (with a width of $4.5 \mathrm{~mm}$ ) was cut resulting in a height of $50 \mathrm{~mm}$ (see Figure 5 (a)), and halved yielding two $50 \mathrm{~mm}$ thick specimen. All cuts were made using a water-cooled concrete saw. After cutting, specimens were conditioned at $50 \pm 3 \%$ relative humidity and $20 \pm 2{ }^{\circ} \mathrm{C}$ for at least one year.

\subsection{X-ray attenuation measurement technique}

To determine the moisture content in the loaded/cracked WST specimens upon exposure to liquid water, non-destructive x-ray attenuation measurements were repeatedly undertaken. For this purpose, a GNI x-ray attenuation measurement system located at the Technical University of Denmark [20] was used, as shown in Figure 2(a). The x-ray measurement system consisted of a polychromatic x-ray source and a $25 \times 25 \mathrm{~mm}^{2} \mathrm{x}$-ray camera housed in a programmable, moveable frame. X-ray source energy settings of $110 \mathrm{keV}$ and $15 \mu \mathrm{A}$ were used for all measurements.

Commonly, the composite system shown in Figure 2(b) is used to derive Eq. 1 [20-22], which relates the reduction in x-ray photons passing through an initially conditioned specimen, $I_{d r y}$, caused by ingress of liquid water, $I_{w e t}$, to the change in moisture content, $\Delta w$

$$
\Delta w=-\frac{\rho_{w}}{\mu_{e f f, w} t} \ln \left(\frac{I_{w e t}}{I_{d r y}}\right)
$$

Where $\rho_{w}$ is the density of water, $\mu_{\text {eff,w }}$ the effective attenuation coefficient of water (i.e., the attenuation coefficient of water as measured through $50 \mathrm{~mm}$ WST specimens), and $t$ the specimen thickness. Results published in [23] indicate that the material type and thickness of the investigated specimen affects the attenuation coefficient of water, necessitating the use of $\mu_{\text {eff, } w}$ as opposed to the linear attenuation coefficient or the attenuation coefficient measured through water alone [23]. 
The measured region, which consisted of 15 individual locations, is shown in Figure 3. At each measurement location, a total integration time of 60 seconds (i.e., 6 images with 10 second exposure time) were captured and summed. Figure 3(b) shows typical images from the 15 measurement locations. Steel fibers are clearly present and the black areas on the perimeter of the measurement area and at the notch are caused by a $6 \mathrm{~mm}$ thick steel shield. Additional details on the $\mathrm{x}$-ray attenuation equipment used and the measurement technique are available in the literature, see e.g., [16,20-24].

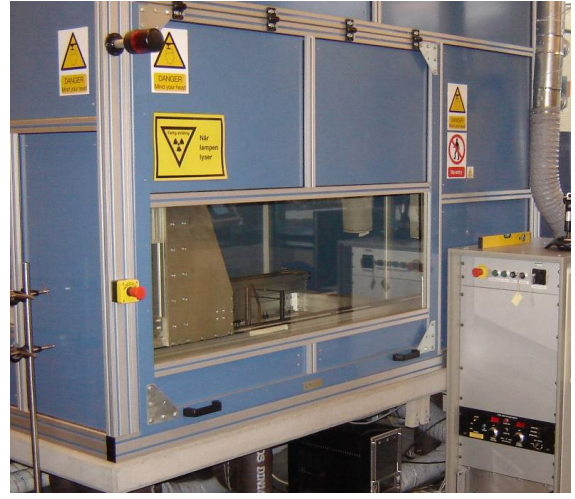

(a)

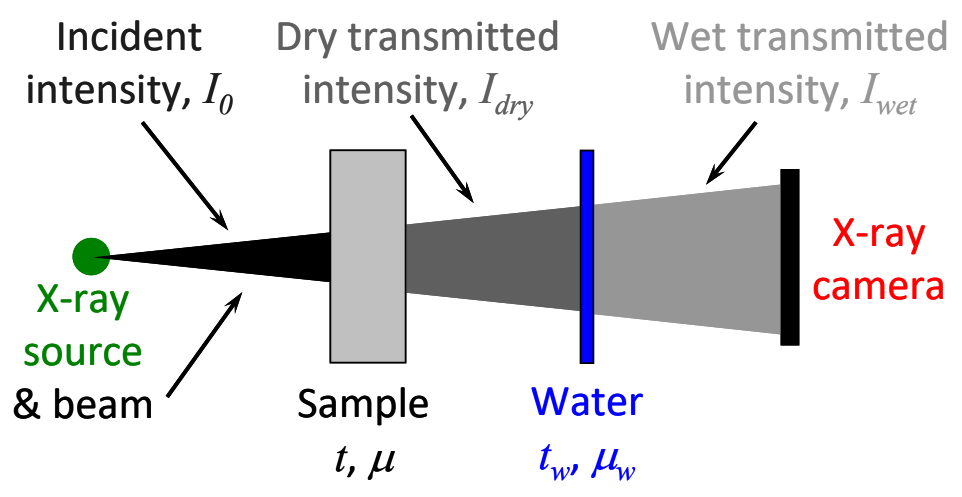

(b)

Figure 2: (a) X-ray attenuation equipment and (b) schematic of moisture ingress measurement described as a composite system of a conditioned sample and a thickness of water.

Over time, variability in the number of x-ray photons detected by the x-ray camera, is observed, which is illustrated schematically in Figure 3(a). Although, dark current images were initially taken and subsequently subtracted from images to reduce measurement errors, the variability leads to image noise, i.e., variation in average number of detected $\mathrm{x}$-ray photons within the same region. For example, the highlighted regions in images 0 and 1 in Figure 3(a) are from the same location in the WST specimen. However, the average number of $\mathrm{x}$-ray photons detected within the regions varies from $35,847.5$ counts in image 0 to 35,311.0 counts in image 1. These overlapping regions were utilized to provide a local normalization factor, $f_{i}$, described by Eq. 2

$$
f_{i}=\frac{\mu_{A, i-1}}{\mu_{B, i}} \text { for } i=1<n
$$

Where $\mu_{A, i-1}$ and $\mu_{B, i}$ are the mean x-ray photon counts from the overlapping regions of images $i-1$ and $i$ and $n$ the number of locations. The normalization factor, $f_{i}$, was then applied to all pixels of image $i$, as shown in Figure 3(a) and the subsequent image $i+1$ is normalized by the same approach. Figure 3(b) shows all the locations of overlapping regions within the WST specimen used for the local normalizations. A batch code for the software package ImageJ, described in [16], was modified to assess the direction of the $\mathrm{x}$-ray source/camera movement, assign the appropriate coordinates of overlapping regions depending on the movement direction, measure $\mu_{A, i-1}$ and $\mu_{B, i}$ values, perform the normalization of summed images, and translate individual images to stitch together an image of the entire measurement area with the propagated local normalization.

Three initial measurements $\left(I_{d r y}\right)$ were taken of the dry specimens and repeated measurements $\left(I_{w e t}\right)$ were taken at approximately 3 minutes, 1, 2, 3, 5, 7, and 24 hours after exposure to liquid water. Finally, global normalization (i.e., normalization of stitched images taken at various times after 
exposure to liquid water), was realized by measuring the mean $\mathrm{x}$-ray photon count from identical regions from all images where the WST specimen remained in the initial condition after 7 hours. It is noted that after 24 hours the moisture front had moved beyond the measured area, making a global normalization impossible. As such, beyond the observation regarding the moisture front, 24-hour results are not presented herein.

Typical computed x-ray attenuation images (Eq. 1), illustrating the impact of the presented local normalization approach, are shown in Figure 4. Figure 4(a) and (b) show typical results without and with the local normalization, respectively. The lower threshold in these images was set to $0 \mathrm{~g} / \mathrm{cm}^{3}$ of water, meaning any grey-to-white-scales indicate the presence of moisture while black indicates either 0 or a negative number. Without the local normalization, boundaries between individual measurement locations are clearly visible and, in certain cases, neighboring locations provide highly different assessments of the moisture conditions. For example, in Figure 4(a) the moisture front appears to end abruptly at the boundary of the second and third row of images, indicating a false ingress of moisture. Previous experience has shown that this issue caused considerable difficulties in analyzing and interpreting results from $\mathrm{x}$-ray attenuation measurements of large specimens that require stitching together of multiple images. The problem is likely caused by the logarithmic subtraction in Eq. 1, which effectively magnifies the impact of local (i.e., from one measurement location to next) and global (i.e., from measurement of $I_{d r y}$ to $I_{\text {wet }}$ at different times) measurement variability. Figure 4(b) and results presented in Section 4.3 indicate local normalization provides a repeatable method to address the issue of measurement variability, allowing detection of the true moisture front. While limited false indications of moisture remain, e.g. in the lower right of Figure 4(b), a marked improvement in the location of the moisture front is clear in Figure 4.
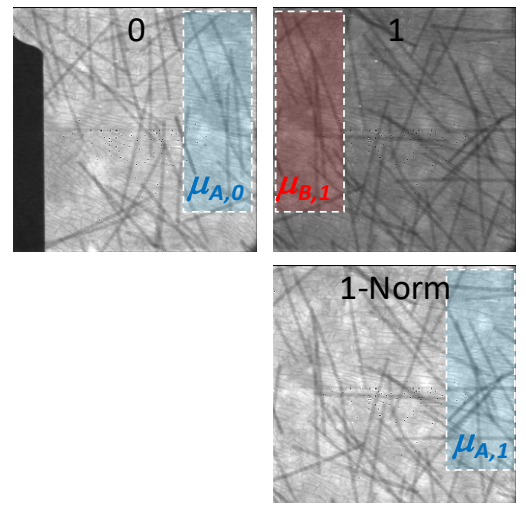

(a)
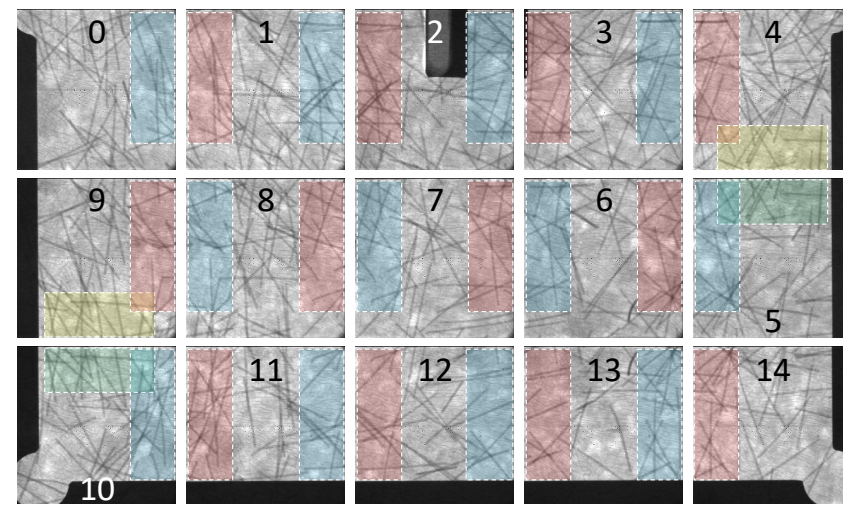

(b)

Figure 3: (a) Description of the local normalization using overlapping regions of individual images (note that contrast was altered in the figure for emphasis) and (b) an example of 15 summed images making up a single measurement, with overlapping regions used for local normalization indicated. 


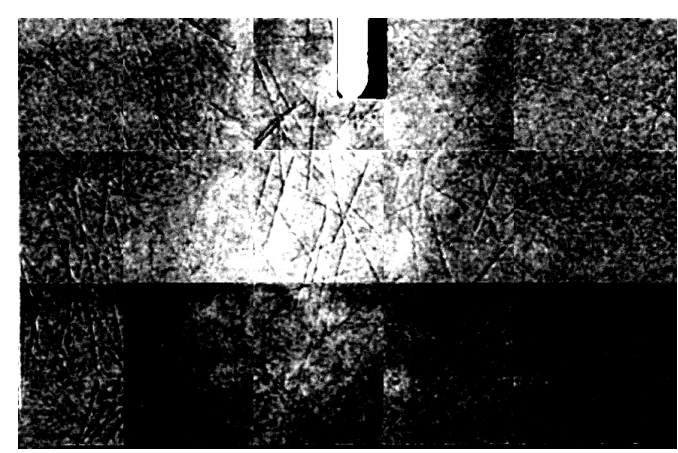

(a)

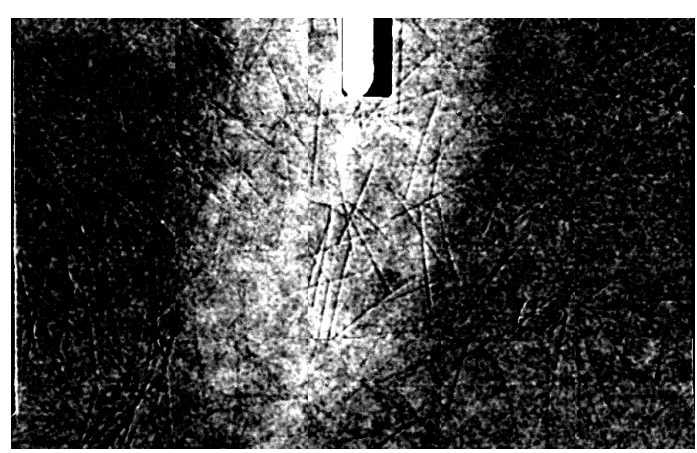

(b)

Figure 4: Calculated x-ray attenuation images (Eq. 1) (a) without and (b) with local normalization approach applied. Please note: white color indicates increase in density due to change in moisture content.

\subsection{Mechanical testing}

\subsubsection{Wedge split testing and inverse analysis with cracked hinge model}

This section provides a basic description of the WST method, with additional details available in the literature, see e.g. [25-27]. Figure 5 shows the implementation of the cracked hinge model (CHM), developed in [25] and [26], to the WST geometry. The CHM simulates an area directly surrounding the propagating crack using the loading and deformation shown in Figure 5(b) and the stress distribution depicted in Figure 5(c). The rigid boundaries of the cracked hinge provide a joint to the bulk (uncracked) specimen, which is controlled by Hooke's law. The comparison and minimization of differences between experimental results and outputs of the CHM via inverse analysis allows for the estimation of the concrete tensile strength, $f_{t}$, elastic modulus, $E$, and cohesive crack relationship, $g(w)$. Throughout the inverse analysis, the bulk specimen is assumed to behave linear elastically, whereas the cracked state is determined by a stress-crack opening relationship as follows:

$$
\sigma= \begin{cases}\sigma(\varepsilon)=E \varepsilon & \text { Pre }- \text { cracked state } \\ \sigma_{w}(w)=g(w) f_{t} & \text { Cracked state }\end{cases}
$$

Where $E$ is the elastic modulus and $\varepsilon$ the elastic strain in the pre-cracked state, and $\sigma_{w}(w)$ is the stresscrack opening relationship (softening curve) with crack opening $w$ in the cracked state. The multi-linear softening curve, $g(w)$, is defined as (for $N>2$ ):

$$
g(w)=b_{i}-a_{i} w \text { with } w_{(i-1)}<w<w_{i}
$$

Where $w_{i}$ corresponds to the intersection of $i$-th and $i+1$-th line and has the form:

$$
w_{i}=\frac{b_{i}-b_{i+1}}{a_{i}-a_{i+1}}
$$

For $i<N$ and:

$$
w_{N}=w_{c}=\frac{b_{N}}{a_{N}}
$$

With $N$ equal to the number of lines in the softening curve. 
The inverse analysis to determine the tensile strength, Young's modulus, and cohesive relation consists then of three steps that are repeated until convergence is reached. In the first step, the Young's modulus is determined from the experimental data corresponding to the elastic loading. Once the Young's modulus is found, the tensile strength and the first descending branch of the softening curve $a_{1}$ are computed. Finally, $N-1$ computations are preformed to find $a_{i}$ and $b_{i}$, with $i=2 \ldots N$ defining the multi-linear softening behavior. Additional details on the CHM and the inverse analysis approach are available in the literature, see e.g., [25-28],

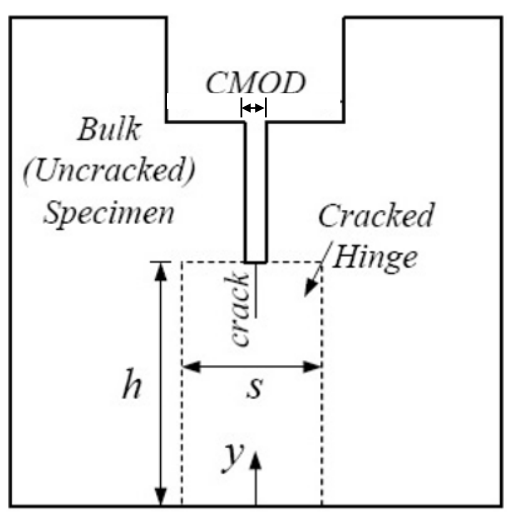

(a)

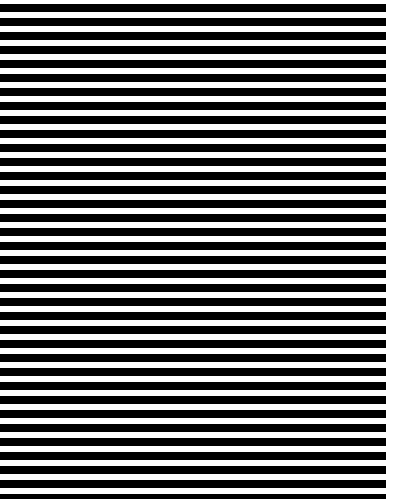

(b)

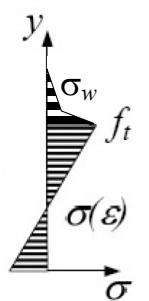

(c)

Figure 5: (a) The wedge split test specimen with cracked hinge model applied (after [26]), (b) loading and deformation of the hinge (after [26]), and (c) the assumed stress distribution (after [26]).

\section{Moisture transport}

Transport of moisture, comprising both liquid and water vapor moisture transport, in porous media was modelled using Richard's equation (see Eq. 7). The solution of the highly non-linear problem was obtained through the definition of appropriate boundary conditions and description of transport coefficients for moisture as well as moisture storage capacity. Defined transport coefficients include, among others, the moisture dependent vapor diffusion coefficient and liquid conductivity. The moisture transport model was then applied to the WST geometry, assuming an initial relative humidity of $50 \%$ within the porous media. Zero flux boundary conditions were assumed for all surfaces except for the recess, notch, crack, and the top surface of the specimen. The recess, notch, and crack were exposed to liquid water at atmospheric pressure. Dirichlet boundary conditions were assumed for the top surface of the WST specimen, i.e., a relative humidity of $65 \%$, based on measured relative humidity in the x-ray chamber during testing.

Crack geometries for the modeled WST specimens were determined based on the CHM described in Section 2.3 and previous experimental findings. While the $\mathrm{CHM}$ is able to estimate the crack profile (see Section 4.1), the model is unable to consider details of the cracking process, such as the presence of isolated microcracks, crack branching, crack tortuosity, etc. Previous observations of the moisture ingress in cracked WST specimens [16] concluded that only a portion of the estimated crack profile behaved as a free surface for water sorption and that a consistent length of the total estimated crack profile appeared to inhibit water sorption. The cracked WST samples used in [16] were subjected to additional investigation in [17] to assess the morphology of the actual cracks. After moisture ingress testing in [16], the specimens were dried and the crack was vacuum-impregnated with florescent epoxy, 
with epoxy introduced through the recess and notch (see [17] for additional details). This procedure filled only the coalesced crack with the florescent epoxy, allowing the coalesced crack length to be measured. Comparisons of measured coalesced crack lengths with the estimated crack profiles in [17] concluded that the CHM estimated crack profile may be divided into a non-coalesced and coalesced crack region, with the non-coalesced crack region following behind the estimated crack tip, as shown in Figure 6 and Figure 8(b). Furthermore, it was observed that the difference between the impregnation depth and estimated crack length (i.e., non-coalesced crack length) had a consistent range of 16.5 to $18.5 \mathrm{~mm}$. Based on the observations presented in $[16,17]$ as well as further studies conducted in $[21,29]$ moisture ingress in the non-coalesced crack region was assumed similar to bulk concrete within the present modelling approach. The remaining crack length was then assumed a coalesced crack, which behaved as a free surface for moisture ingress. An overview of the assumptions for modelling the moisture ingress in cracked porous media is given in Figure 6.

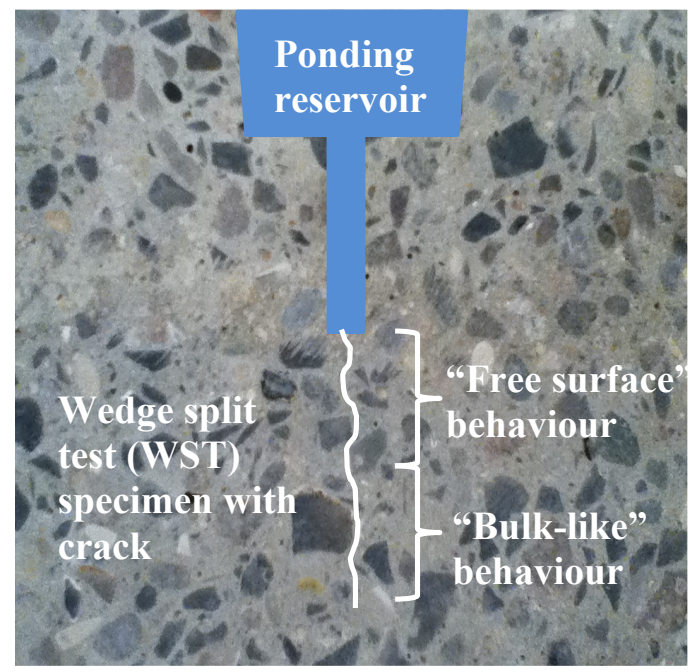

Figure 6: WST specimen with assumptions on the crack behavior for modelling the ingress of moisture in porous media.

\subsection{Conductivity approach}

Assuming that contributions due to air transfer, gravity, radiation, liquid transport due to temperature gradients, and effects of the gaseous phase on the moisture and heat storage are negligible as well as temperatures remain below the boiling temperature of water [30], the transport equation to describe liquid and water vapor moisture transport in porous media may be given as follows (see e.g., [31-33]):

$$
\frac{\partial m_{l+v}}{\partial t}=-C \frac{\partial p_{c}}{\partial t}=-\nabla\left(\frac{D_{v}\left(\Theta_{l}\right)}{R_{v} T} \nabla p_{v}+K_{l}\left(\Theta_{l}\right) \nabla p_{c}\right)
$$

Where, $m_{l+v}$ is the sum of the water vapour and liquid water content, $C$ the moisture capacity, $p_{c}$ the capillary pressure, $D_{v}$ the vapour diffusion coefficient, $\theta_{l}$ the moisture content, $R_{v}$ the gas constant of water vapour, $T$ the temperature, $p_{v}$ the vapour pressure, $K_{l}$ the liquid conductivity coefficient, and $t$ the time. Using Kelvin equation and capillary pressure, $p_{c}$, as the common driving potential for vapour and liquid water transport, Eq. 7 yields: 


$$
\frac{\partial m_{l+v}}{\partial t}=-C \frac{\partial p_{c}}{\partial t}=-\nabla\left(\frac{D_{v}\left(\Theta_{l}\right)}{R_{v} T} \frac{p_{v, s a t} \phi}{\rho_{l} R_{v} T} \nabla p_{c}+K_{l}\left(\Theta_{l}\right) \nabla p_{c}\right)
$$

Where $p_{v, \text { sat }}$ is the saturation vapour pressure and $\varphi$ the relative humidity. To solve Eq. 8 , appropriate material specific information on $i$ ) the capillary pressure curve describing the moisture storage of the porous media, $i$ ) the vapour diffusion coefficient, and $i i i)$ the liquid water conductivity are needed.

In the present modelling approach, the capillary pressure curve is assumed to be sufficiently described by a bimodal function of a van Genuchten type [34]:

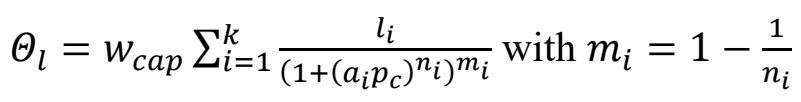

Where $w_{c a p}$ is the capillary moisture content, $a, n$, and $m$ shape parameters, and $l$ a weighing factor. The chosen parameters for the present model to describe the capillary pressure curve are given in Table 1. The pore volume distribution of the porous media can be obtained from the derivation of Eq. 9 with respect to the capillary pressure and the use of Young's - Laplace equation to relate the capillary pressure, $p_{c}$, and the pore radius, $r$ :

$$
p_{c}=\frac{2 \gamma \cos \theta}{r}
$$

Where $\gamma$ is the surface tension and $\theta$ the wetting angle.

Vapour flow transport within porous media is described as follows in the present modelling approach:

$$
D_{v}\left(\Theta_{l}\right)=\frac{D_{v, \text { air }}}{\mu_{d r y}} f_{v}\left(\Theta_{l}\right)
$$

Where $D_{v, \text { air }}$ is the vapour diffusion coefficient of air, $\mu_{d r y}$ the vapour diffusion resistance number, and $f_{v}\left(\theta_{l}\right)$ the vapour diffusion scaling function. The vapour diffusion coefficient of air is described as follows according to the relation given in [35]:

$$
D_{v, \text { air }}=0.083 \frac{p_{0}}{p}\left(\frac{T}{273.15}\right)^{1.81}
$$

Where $p_{0}$ is the reference gas pressure. The applied vapour diffusion scaling function was proposed by Scheffler \& Plagge [36] and is based on a mechanistic modelling approach taking into account the impact of moisture content and the microstructure of the porous media on vapour diffusion. The vapour diffusion scaling function may be approximated as follows:

$$
f_{v}\left(\Theta_{l}\right)=\frac{1-\frac{\theta_{l}}{\theta_{p o r}}}{\left(\frac{\theta_{l}}{\theta_{p o r}}\right)^{n_{s p}}+\left(1-\frac{\theta_{l}}{\theta_{p o r}}\right)^{2}\left(1-\left(\frac{\theta_{l}}{\theta_{p o r}}\right)^{n_{s p}}\right)}
$$

Where $\theta_{\text {por }}$ is porosity and $n_{s p}$ a modelling parameter.

Within the present modelling approach, the liquid moisture flow in porous media is described as follows: 


$$
K_{l}\left(\Theta_{l}\right)=K_{l, r e l}\left(\Theta_{l}\right) f_{l}\left(\Theta_{l}\right) K_{l, s a t}
$$

Where $K_{l, \text { rel }}$ is the relative liquid conductivity containing information on the pore structure of the porous media, $K_{l, \text { sat }}$ the liquid conductivity at saturation, and $f_{l}\left(\theta_{l}\right)$ a liquid flow scaling function. The function $f_{l}\left(\theta_{l}\right)$ is thereby, similar to the vapour flow scaling function, based on a mechanistic modelling approach proposed by Scheffler \& Plagge [36]. For the determination of the relative liquid conductivity the approach derived by Mualem [37] is employed:

$$
K_{l, r e l}\left(\Theta_{l}\right)=\left[\frac{\int_{0}^{\Theta_{l}} p_{c}(\theta)^{-1} d \theta}{\int_{0}^{\theta_{p o r}} p_{c}(\theta)^{-1} d \theta}\right]^{2}
$$

However, instead of the tortuosity factor proposed in [37], the liquid flow scaling function derived in $[36,38]$ is used, which may be described as follows:

$$
f_{l}\left(\Theta_{l}\right)=\frac{\left(\frac{\theta_{l}}{\theta_{\text {por }}}\right)^{n_{s p}}}{\left(\frac{\theta_{l}}{\theta_{\text {por }}}\right)^{n_{s p}}+\left(1-\frac{\theta_{l}}{\theta_{\text {por }}}\right)^{2}\left(1-\left(\frac{\theta_{l}}{\theta_{\text {por }}}\right)^{n_{s p}}\right)}
$$

An overview of the required input parameters for the moisture transport modelling approach is given in Table 1. Moreover, typical moisture transport input parameters, i.e. the moisture storage function and its derivation, the pore size distribution, along with the vapor and liquid flow transport coefficients, for the material investigated in this study are presented in Figure 7. More detailed information on the mechanistic model and the derivation of the liquid and vapor flow scaling functions can be found in $[36,38]$.

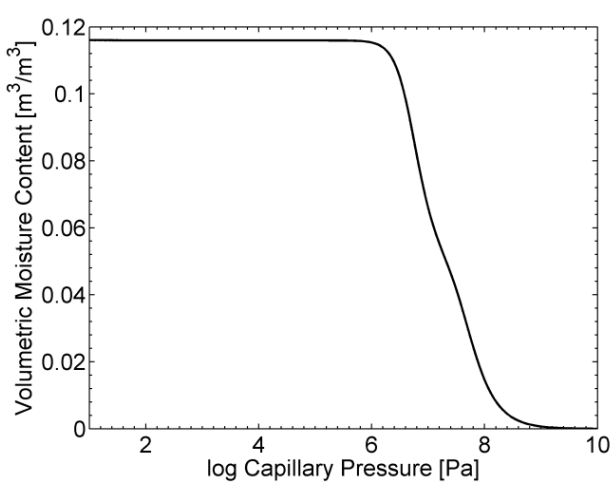

(a)

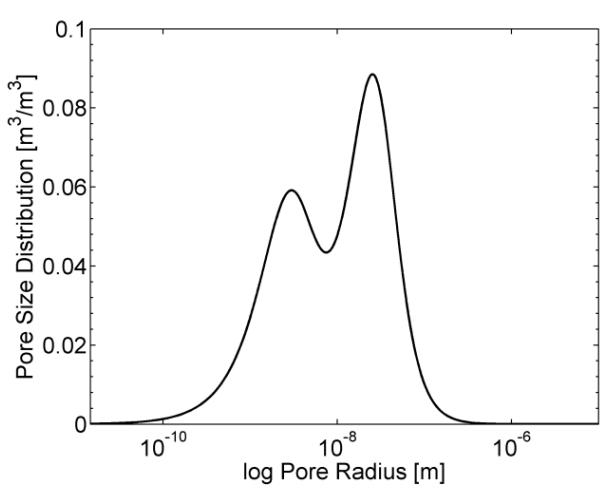

(b) 


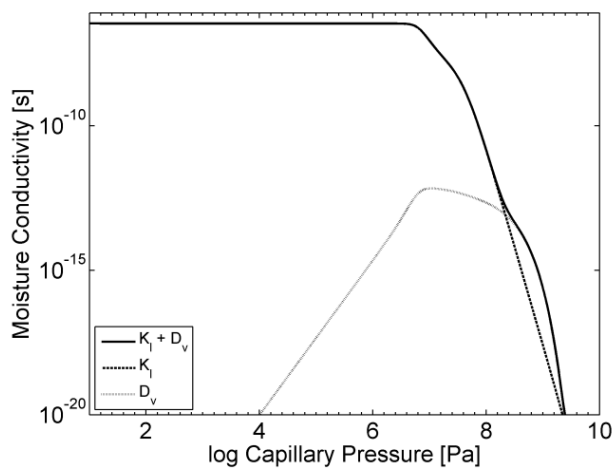

(c)

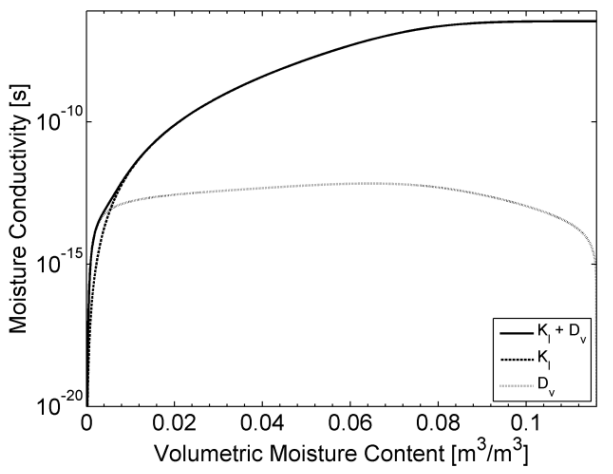

(d)

Figure 7: Transport proprties for modelling of coupled vapor and liquid moisture transport in the investigated material: (a) moisture storage function, (b) pore size volume distribution derived from the moisture storage function. Moisture conductivity (solid black line indicates sum of liquid (broken line) and vapor (dotted line) conductivity) as a function of (c) logarithm of capillary pressure and (d) volumetric water content.

Table 1: Model parameters for moisture transport model.

\begin{tabular}{ccccc}
\hline & Model Parameter & Symbol & Value & Unit \\
\hline & Non-physical model parameter & $l_{1}$ & 0.426 & - \\
& Non-physical model parameter & $l_{2}$ & 0.574 & - \\
& Non-physical model parameter & $n_{1}$ & 2.34 & - \\
& Non-physical model parameter & $n_{2}$ & 2.68 & - \\
Moisture storage & Non-physical model parameter & $a_{1}$ & $2.4 \mathrm{E}-08$ & - \\
parameters & Non-physical model parameter & $a_{2}$ & $2.5 \mathrm{E}-07$ & - \\
& Non-physical model parameter & $m_{1}$ & $1-1 / n_{1}$ & - \\
& Non-physical model parameter & $m_{2}$ & $1-1 / n_{2}$ & - \\
& Maximum moisture content & $\theta_{\max }$ & 0.116 & {$\left[\mathrm{~m}^{3} / \mathrm{m}^{3}\right]$} \\
\hline \multirow{2}{*}{$\begin{array}{c}\text { Moisture transport } \\
\text { parameters }\end{array}$} & Saturated conductivity & $K_{l, s a t}$ & $3.5 \mathrm{E}-7$ & {$[\mathrm{~m} / \mathrm{s}]$} \\
& Vapor diffusion resistance number & $\mu$ & 30 & - \\
\hline
\end{tabular}

\section{Experimental and numerical results}

\subsection{Cracked hinge model}

Results of the inverse analysis by means of the cracked hinge model (CHM), i.e., estimations of Young's modulus, tensile strength, and cohesive relation of the material investigated, are provided in Table 2, while estimated crack profiles at various stages of loading/cracking are shown in Figure 8.

As shown in Figure 8, the CHM provides an estimate of the crack opening displacement (COD) below the WST specimen notch. The maximum crack width in all crack profiles is found at the crack edge (i.e., at the bottom of the notch) and the CODs decrease linearly towards the crack tip. Results of the 
inverse analysis indicate cracking has occurred at $70 \%$ of the peak load, although only a minute crack is estimated, with a length of approximately $4.8 \mathrm{~mm}$ and a maximum COD of approximately $0.9 \mu \mathrm{m}$ (see Figure 8(a)). Additional deformation causes the estimated crack length and CODs to increase to maxima of approximately $45 \mathrm{~mm}$ and $0.23 \mathrm{~mm}$, respectively for specimens with a CMOD of $0.4 \mathrm{~mm}$.

As seen in Figure 8(b), beyond peak loading, specimen identification is based on the measured CMOD. As described in Section 2, the CMOD was measured directly above the notch, at the bottom of the recess in the WST specimen. While the CMOD is a convenient naming convention, it is important to note that the estimated COD reflects the actual crack width that affects the moisture ingress behavior. Table 3 presents the crack edge opening displacement (CEOD) and crack length estimated by the CHM for each specimen. As shown in Table 3, the CEOD for the $0.10 \mathrm{~mm}$ CMOD sample is estimated to be $0.043 \mathrm{~mm}$.

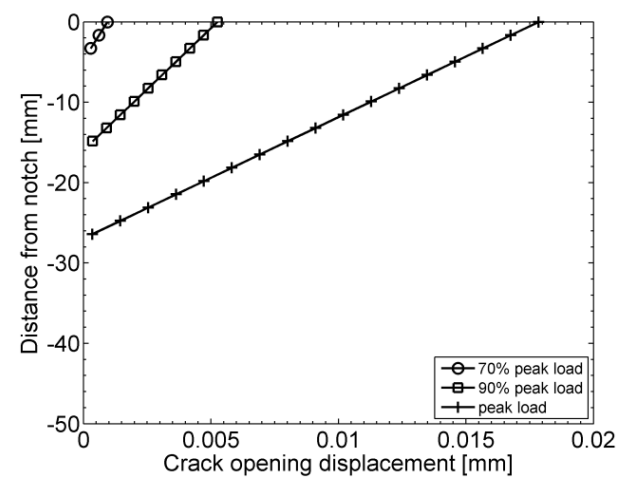

(a)

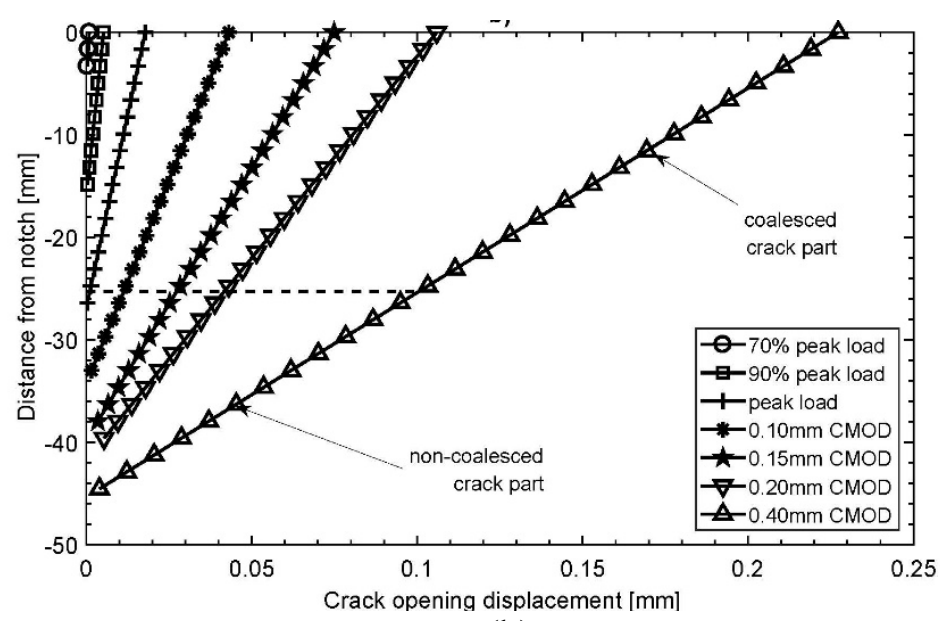

(b)

Figure 8: Estimated crack profiles from the CHM for the investigated material at varying stages of loading/cracking, (a) for 70\%, 90\%, and peak load and (b) for all investigated loading/cracking states. By means of example, the assumed crack geometry used in transport modelling is shown for the 0.40 mm CMOD specimen. 
Table 2: Material properties of investigated material by inverse analysis applying CHM.

\begin{tabular}{cccc}
\hline Parameter & & Value & Unit \\
\hline Young's modulus & $E$ & 31.00 & {$[\mathrm{GPa}]$} \\
Tensile strength & $f_{t}$ & 3.30 & {$[\mathrm{MPa}]$} \\
& $a_{1}$ & 11.30 & {$[\mathrm{MPa} / \mathrm{MPa} / \mathrm{mm}]$} \\
Modelling parameters to & $b_{1}$ & 1.00 & {$[\mathrm{MPa} / \mathrm{MPa}]$} \\
define multi-linear & $a_{2}$ & 1.62 & {$[\mathrm{MPa} / \mathrm{MPa} / \mathrm{mm}]$} \\
softening curve, see also & $b_{2}$ & 0.44 & {$[\mathrm{MPa} / \mathrm{MPa}]$} \\
Eq. 5 & $a_{3}$ & 0.10 & {$[\mathrm{MPa} / \mathrm{MPa} / \mathrm{mm}]$} \\
& $b_{3}$ & 0.10 & {$[\mathrm{MPa} / \mathrm{MPa}]$} \\
\hline
\end{tabular}

Table 3: Estimated CEOD and crack length for each specimen.

\begin{tabular}{ccc}
\hline \multirow{2}{*}{ Specimen Id } & \multicolumn{2}{c}{ Estimated crack geometry } \\
\cline { 2 - 3 } & CEOD [mm] & Crack Length $[\mathrm{mm}]$ \\
\hline 70\% Peak Load & 0.001 & 4.75 \\
90\% Peak Load & 0.005 & 15.95 \\
Peak Load & 0.018 & 26.93 \\
$0.10 \mathrm{~mm}$ CMOD & 0.043 & 34.30 \\
$0.15 \mathrm{~mm}$ CMOD & 0.075 & 38.49 \\
$0.20 \mathrm{~mm}$ CMOD & 0.106 & 40.73 \\
$0.40 \mathrm{~mm}$ CMOD & 0.227 & 44.56 \\
\hline
\end{tabular}

\subsection{X-ray attenuation measurements}

Results of x-ray attenuation measurements, providing contour plots of the moisture content in loaded/cracked WST specimens exposed to liquid water, are given in Figs. 9 to 15. The contour plots were derived from images similar to that shown in Figure 4 and calculated using Equation 1 after various times of exposure to liquid water. The white area in the contour plots identifies the location of the notch and a steel shield that was used to cover the notch. The steel shield causes a small area near the notch to be incalculable due to the high attenuation provided by $6 \mathrm{~mm}$ of steel in addition to $50 \mathrm{~mm}$ of concrete. The steel shield and notch can be seen in Figure 4.

Figs. 9 to 15 clearly show that moisture ingress was detected by the x-ray attenuation measurement technique and highlight the impact of loading and cracking on the moisture ingress. Loading to 70 and $90 \%$ of the peak load has a limited impact on the moisture ingress behavior of the tested samples. At peak load, a clear protrusion of the moisture front into the depth of the sample is apparent after 3 minutes of exposure to water. It is noted that the CHM estimated crack length at peak load is $26.93 \mathrm{~mm}$ (see Table 3), which exceeds the 16.5 to $18.5 \mathrm{~mm}$ non-coalesced crack length discussed in Section 4.1. With the further increase in the CHM estimated crack length associated with the cracked samples (i.e., $0.10-0.40 \mathrm{~mm}$ CMOD specimens), the depth of moisture ingress steadily increases.

Results in Figures 9 to 15 indicate the moisture front is easily detected, aided by the normalization process described in Section 2.2. However, results presented in Figs. 9 to 13 also provide indications 
that additional improvements in the measurement technique may be realized. Comparison of measurements from individual test specimens at different times shows that fluctuations in the moisture contents were detected. For example, in Figure 11 moisture contents at 2 hours (Figure 11 (c)) appear in general to be higher, as indicated by the orange to red colors, than the preceding and following measurements at 1 and 3 hours (Figure 11 (b) and (d), respectively). Such a momentary increase in the moisture content is unexpected.

\subsection{Comparison between experimental and numerical results}

Figs. 9 to 15 also provide results of the moisture transport model presented in Section 3. Results of the numerical simulation are represented using isolines, which match the contours of the experimental data. Initially, the moisture transport model was calibrated determining three model parameters, $n_{s p}, \mu$, and $K_{l, s a t}$, for which data presented in Figure 9 (70\% peak load sample) was used. The model parameters were found to be 1,30 , and $3.5 \times 10^{-7} \mathrm{~m} / \mathrm{sec}$ (see also Table 1), respectively, and were held constant throughout all simulations. Similar values for the liquid conductivity at saturation, $K_{l, \text { sat }}$, have been reported in the literature, see e.g., $1.5 \times 10^{-6} \mathrm{~m} / \mathrm{sec}$ for cement paste with a water-to-cement ratio of 0.3 [39], $1.0 \times 10^{-13}$ for the permeability $\left(\approx 1.0 \times 10^{-6}\right.$ for liquid conductivity) of mortar [40], and $7.1 \times 10^{-}$

${ }^{14}$ for the permeability $\left(\approx 6.9 \times 10^{-7}\right.$ for liquid conductivity) of concrete with a w/c of 0.45 [41].

As previously stated, the crack geometry was determined using results of the CHM and epoxy impregnation [16,21], assuming a constant length from the crack tip of the estimated crack consisted of isolated micro-cracking with bulk-like moisture transport properties. For all simulations, a constant length of the isolated micro-cracking of $18.5 \mathrm{~mm}$ was used. The estimated crack lengths for the $70 \%$ and $90 \%$ peak load specimens did not reach a total length of $18.5 \mathrm{~mm}$; therefore, ingress was modelled in both cases without a crack.

In general, it can be seen from the results presented in Figs. 9 to 15 that the transport model appears to accurately estimate the moisture front as well as impact of cracking using the simplified crack geometry proposed in [16,21]. Very good agreements between experimental data and model predictions with respect to the extent of moisture ingress, both horizontally and vertically, can be observed for WST specimens with a crack mouth opening displacement (CMOD) up to $0.15 \mathrm{~mm}$.

For WST specimens with a CMOD of $0.20 \mathrm{~mm}$ (Figure 14) and $0.40 \mathrm{~mm}$ (Figure 15), respectively, a larger deviation between experimental data and model predictions are seen. In both cases, the ingress model with a simplified crack geometry underestimates the impact of the crack on the vertical ingress of moisture. This underestimation by the model occurs at all exposure times and yields a distinct different shape of the measured and modeled moisture ingress front. Experimental results indicate the water penetrated the entire (measured/observed) depth of the sample quickly and penetrated laterally thereafter, resulting in a near vertical moisture ingress front. The model still indicates a blunting of the moisture ingress into the depth of these samples, resulting in a rounded ingress profile. The different in moisture ingress front is suspected to be a result of the crack development in the WST sample becoming unstable for the larger CMOD samples (i.e., 0.20 and $0.40 \mathrm{~mm}$ ). Estimated crack lengths in Table 3 show a limited un-cracked depth remained in these cases and it may be possible that further cracking occurred due to handling, etc. The poor correlation between the experimental and model results was therefore likely caused by exceeding a stable cracking situation in the selected specimen geometry. Nevertheless, the 0.20 and $0.40 \mathrm{~mm}$ CMOD sample results are included herein to highlight this perceived limitation of the test method to provide stable crack geometries. 
The local variations in the moisture content, characteristic for the experimental data, were not observed in the model results. This contradiction is due to the use of a homogeneous moisture storage function in the model, while the cement content (or inversely, aggregate content) of the specimens varies naturally with location in the test specimens.

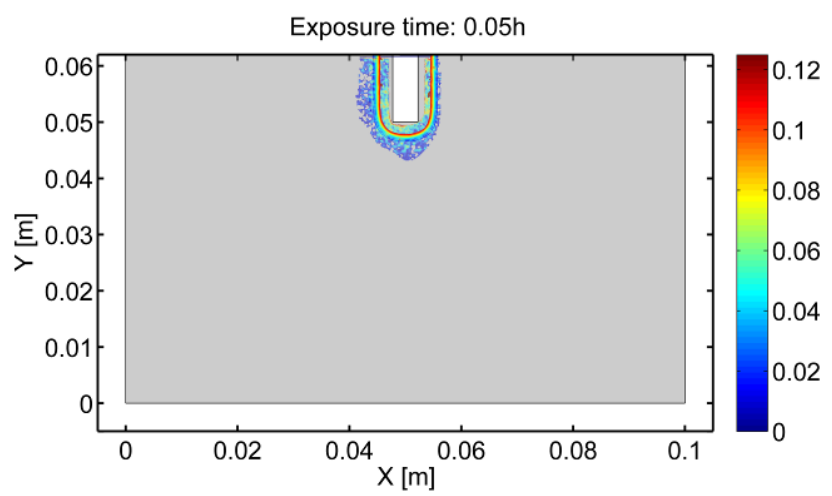

(a)

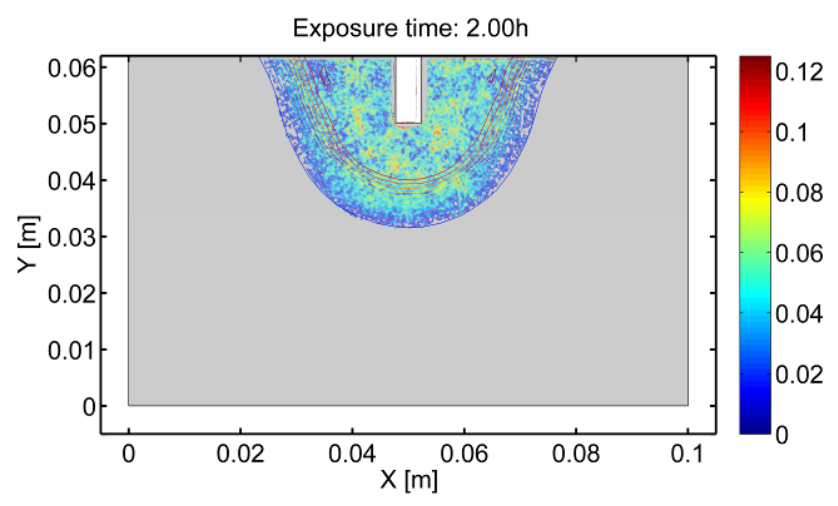

(c)

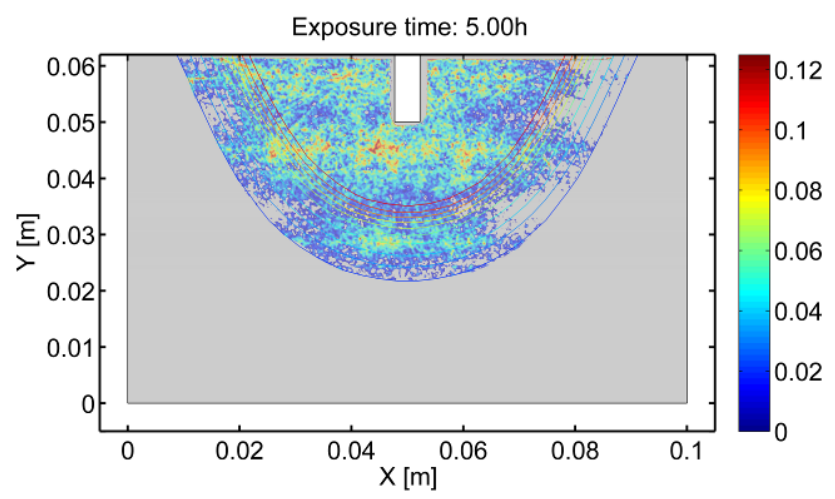

(e)

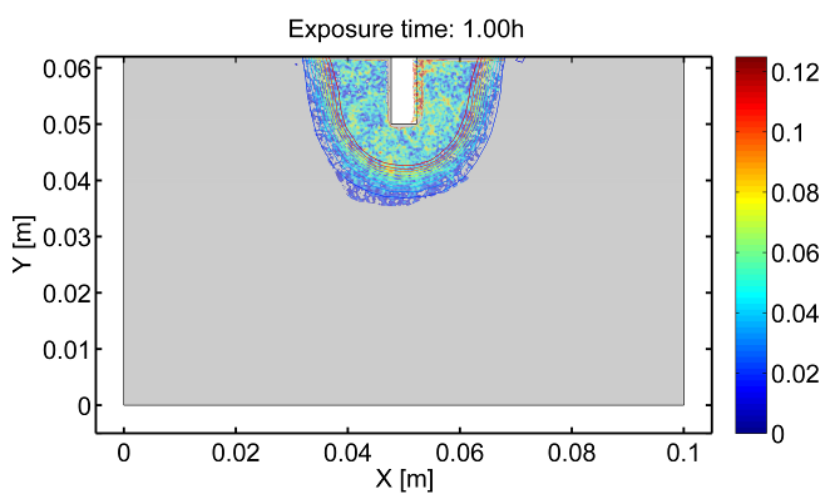

(b)

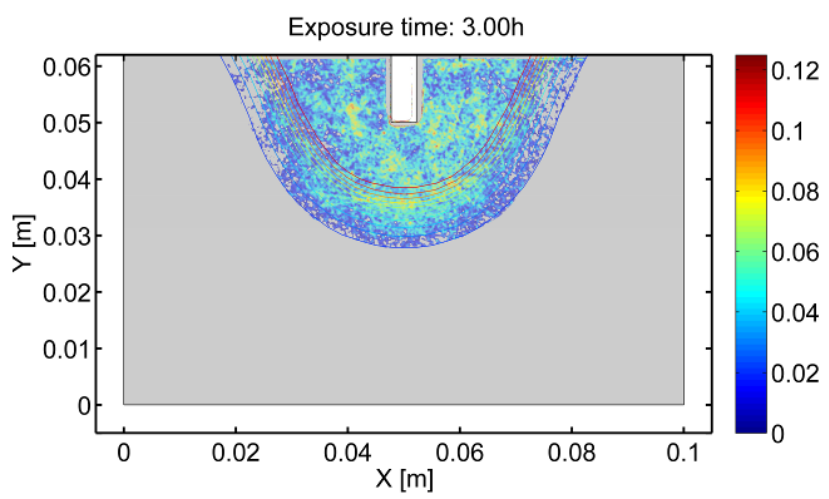

(d)

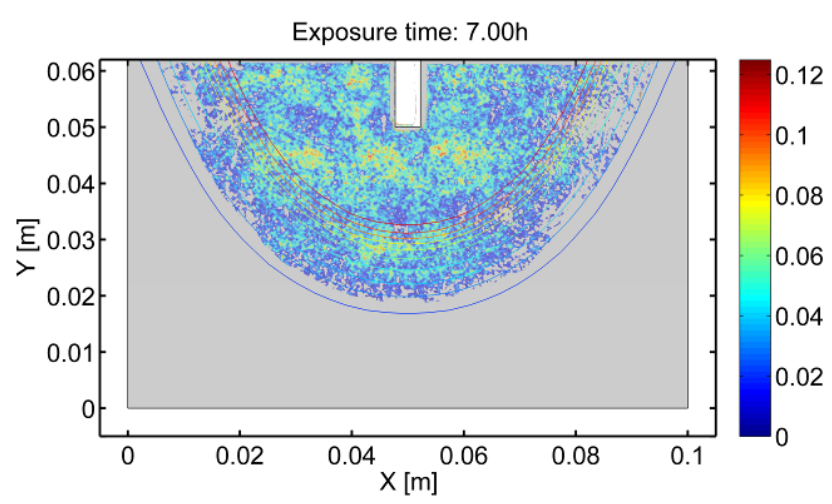

(f)

Figure 9: Experimental and modelled ingress results for 70\% peak load WST specimen after various hours of exposure to liquid water. Please note: color bar indicates (measured and modelled) moisture content in $\mathrm{m}^{3} / \mathrm{m}^{3}$. 


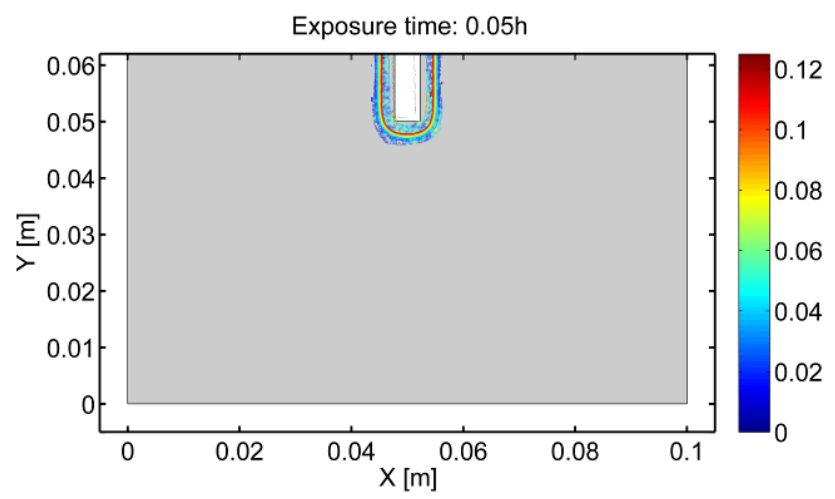

(a)

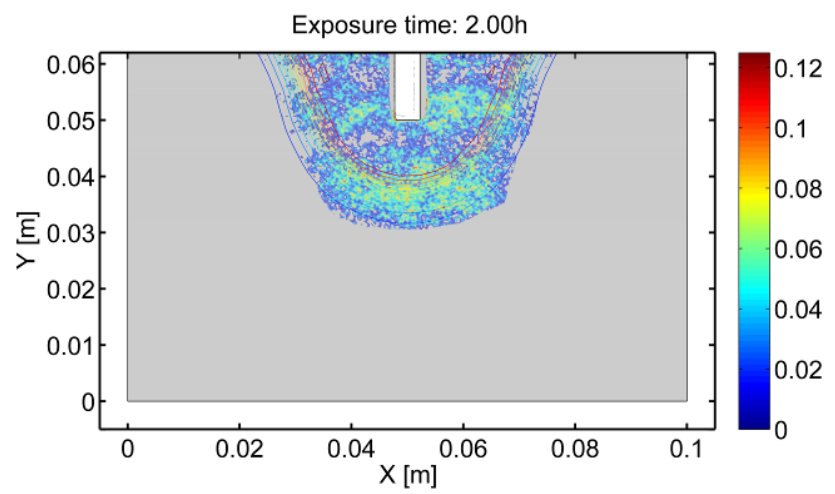

(c)

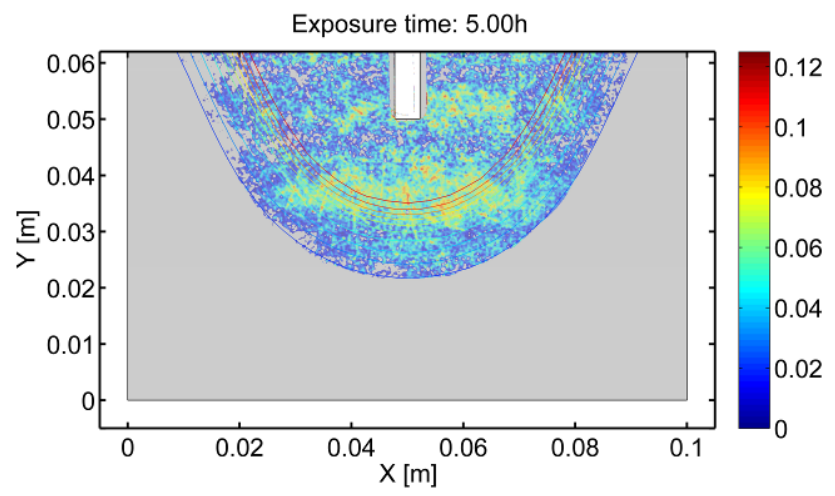

(e)

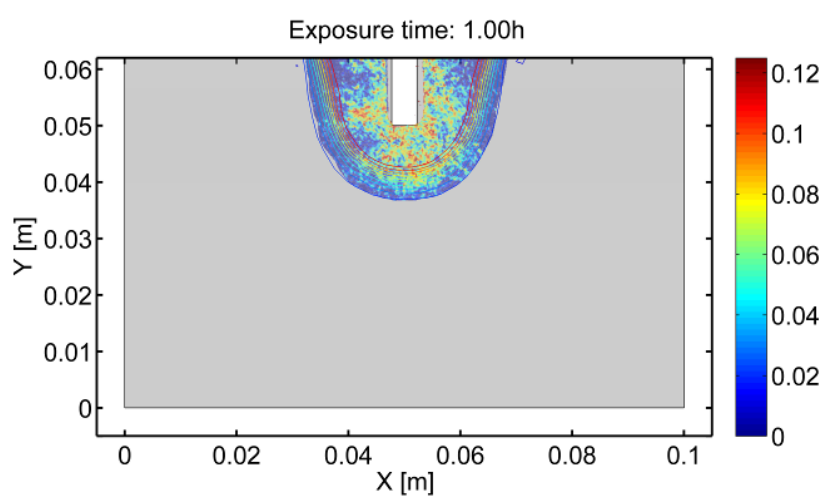

(b)

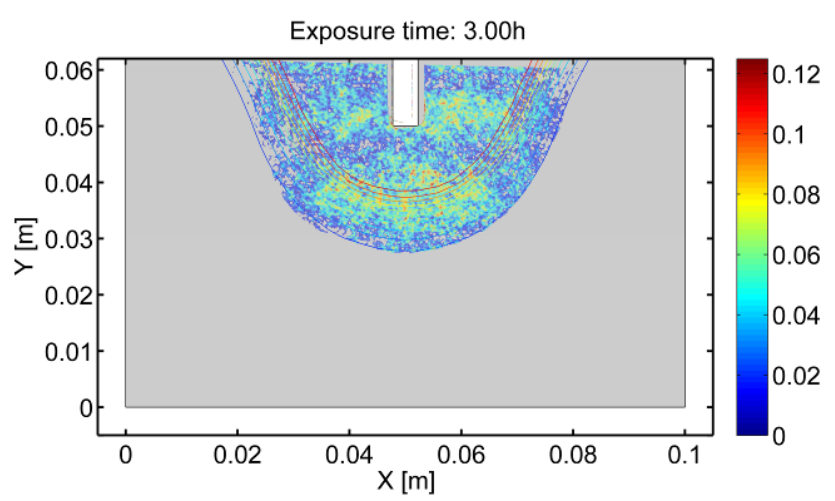

(d)

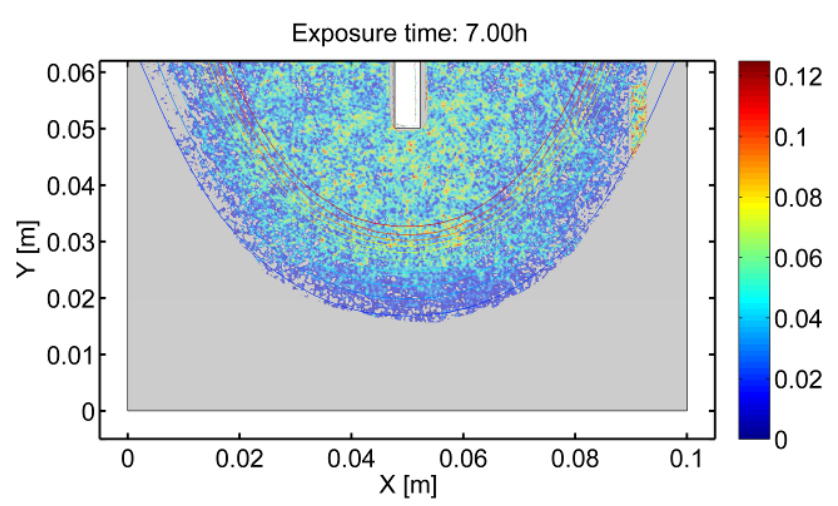

(f)

Figure 10: Experimental and modelled ingress results for $90 \%$ peak load WST specimen after various hours of exposure to liquid water. Please note: color bar indicates (measured and modelled) moisture content in $\mathrm{m}^{3} / \mathrm{m}^{3}$. 


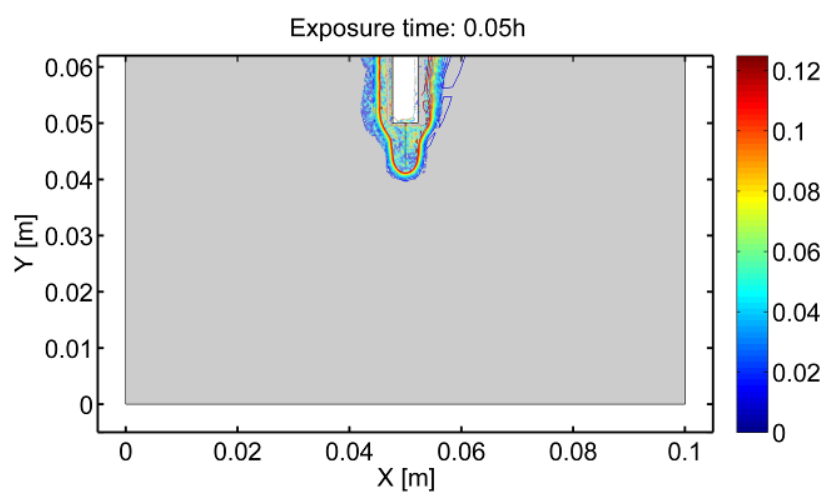

(a)

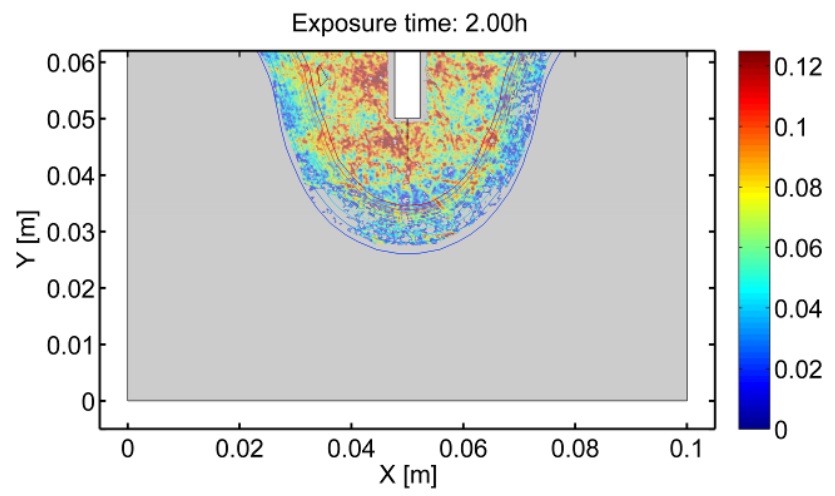

(c)

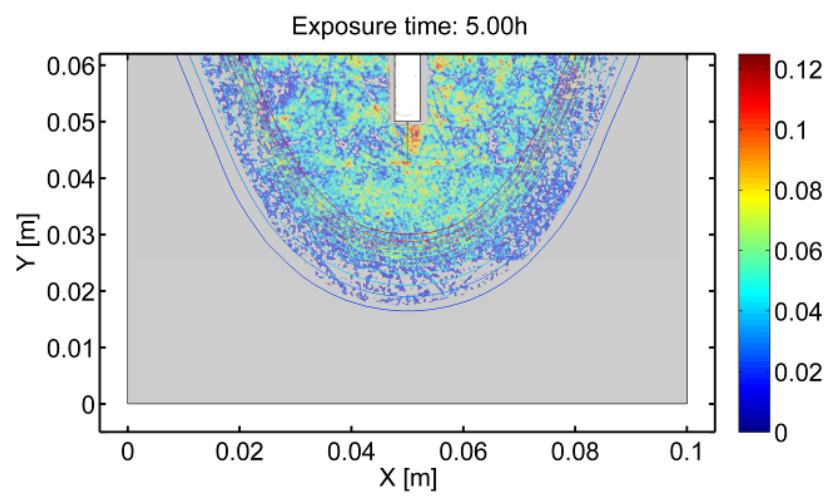

(e)

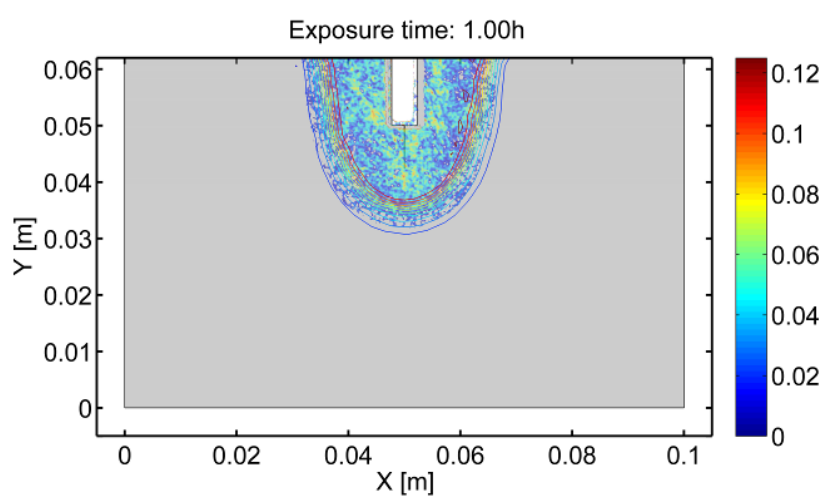

(b)

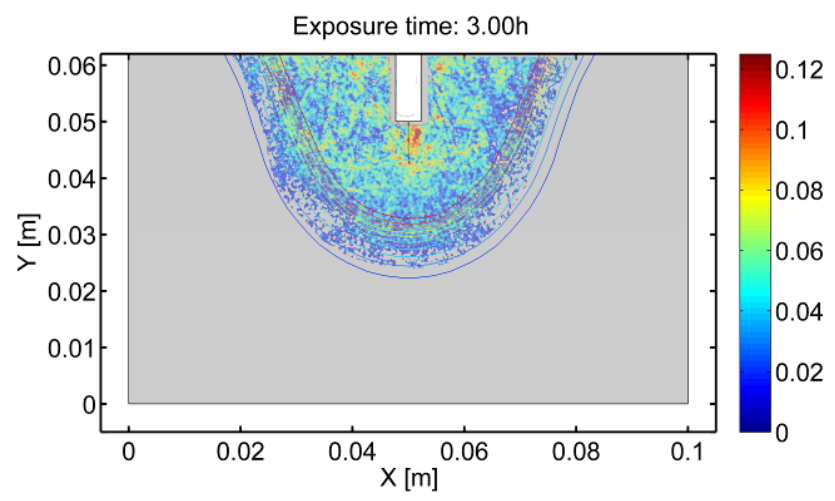

(d)

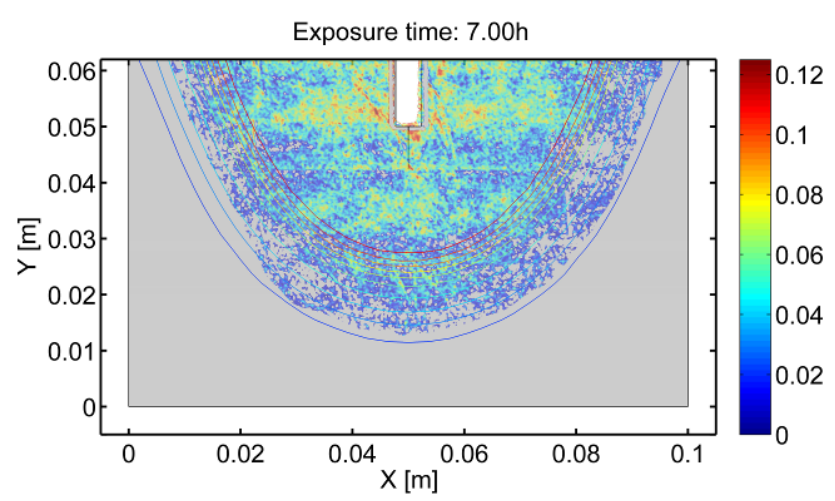

(f)

Figure 11: Experimental and modelled ingress results for peak load WST specimen after various hours of exposure to liquid water. Please note: color bar indicates (measured and modelled) moisture content in $\mathrm{m}^{3} / \mathrm{m}^{3}$. 


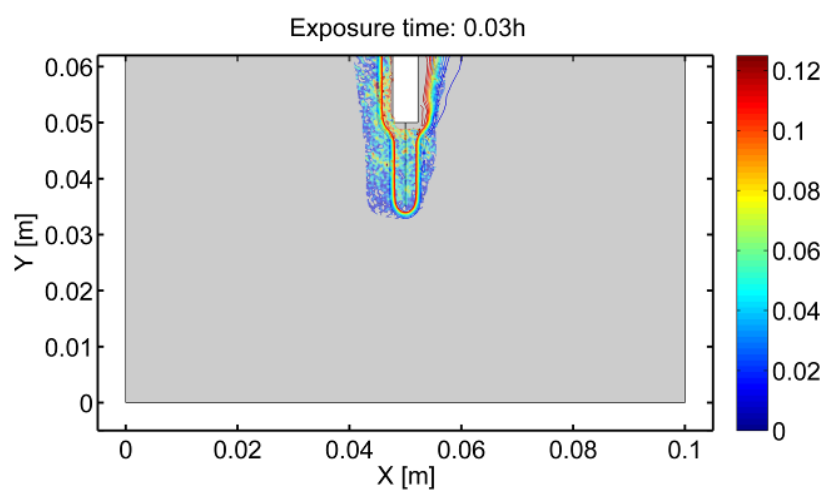

(a)

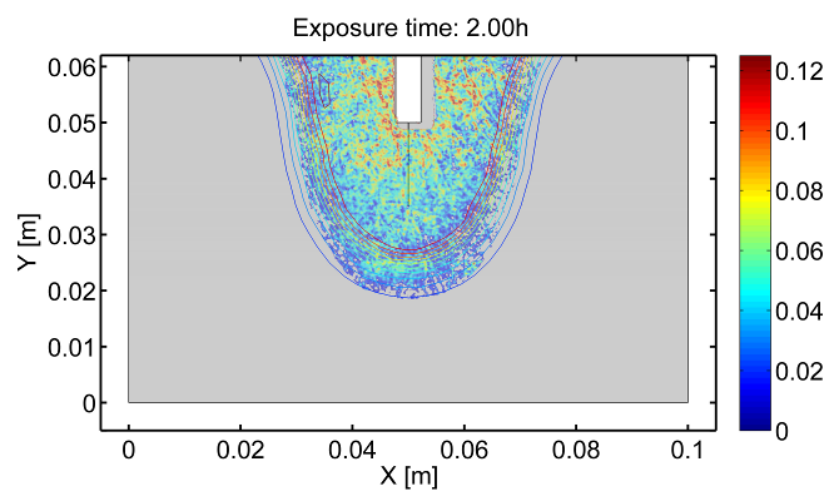

(c)

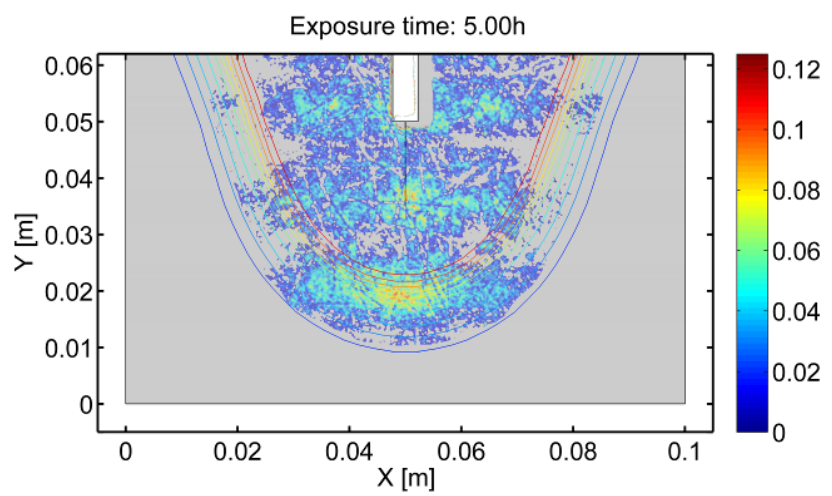

(e)

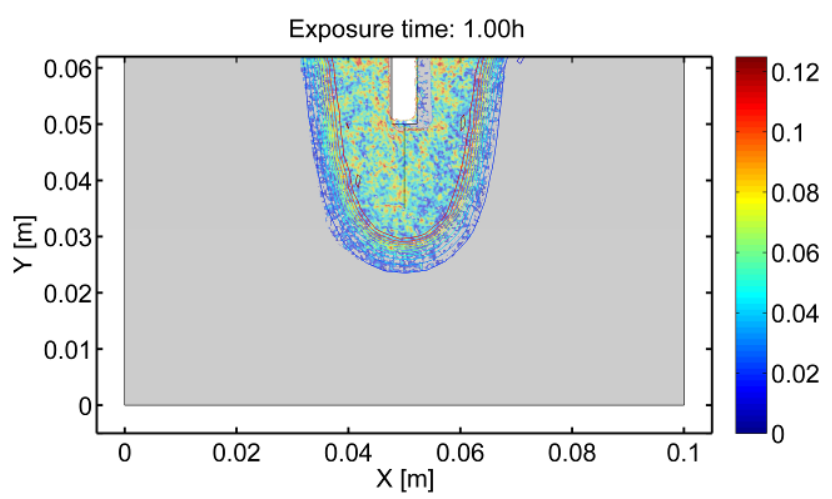

(b)

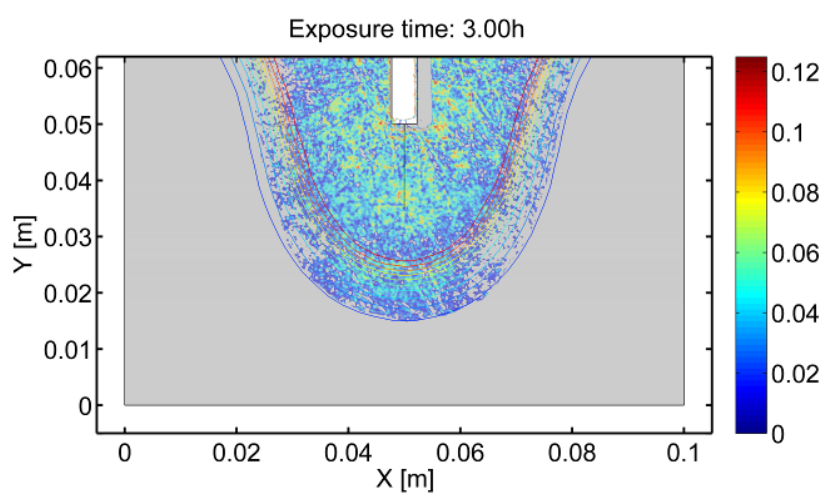

(d)

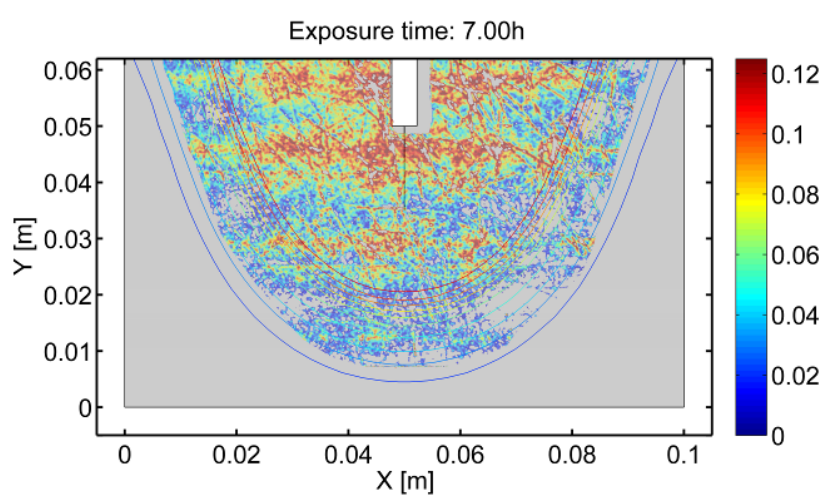

(f)

Figure 12: Experimental and modelled ingress results for $0.10 \mathrm{~mm}$ CMOD WST specimen after various hours of exposure to liquid water. Please note: color bar indicates (measured and modelled) moisture content in $\mathrm{m}^{3} / \mathrm{m}^{3}$. 


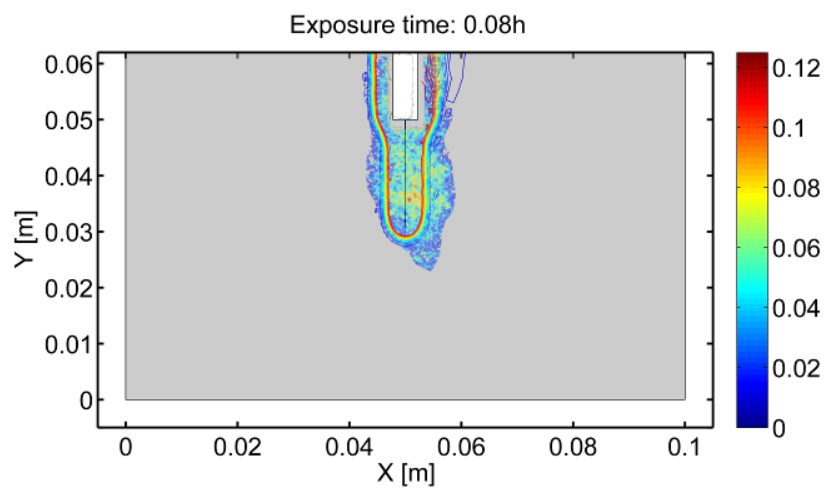

(a)

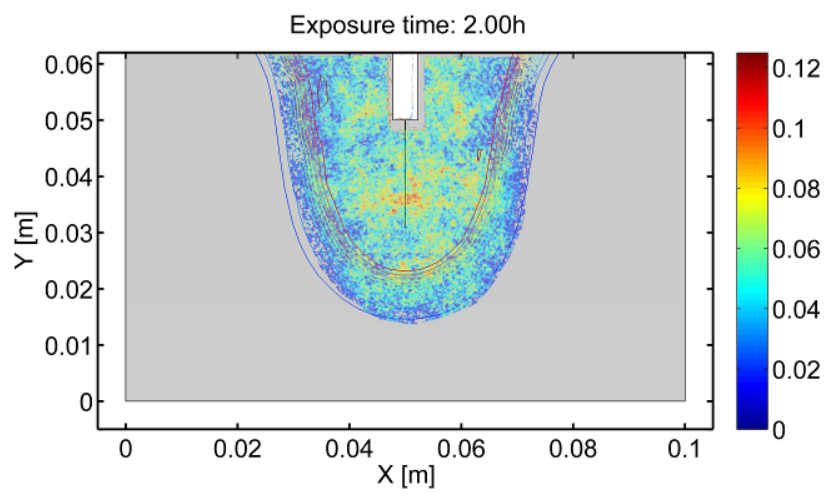

(c)

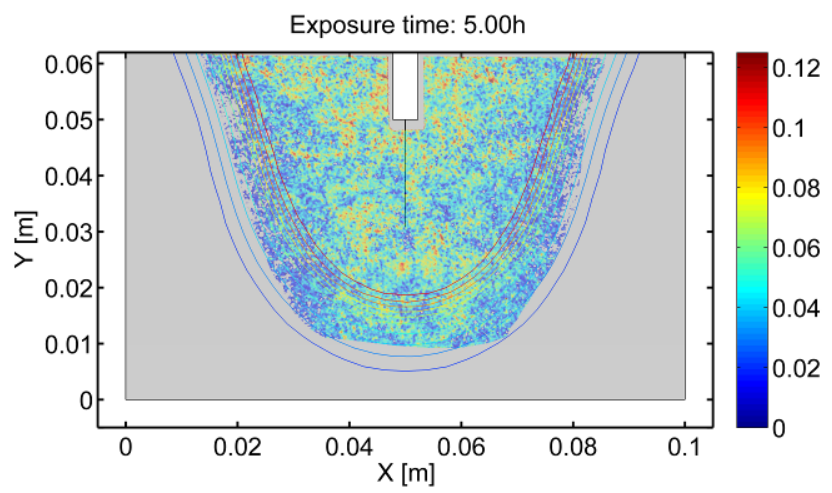

(e)

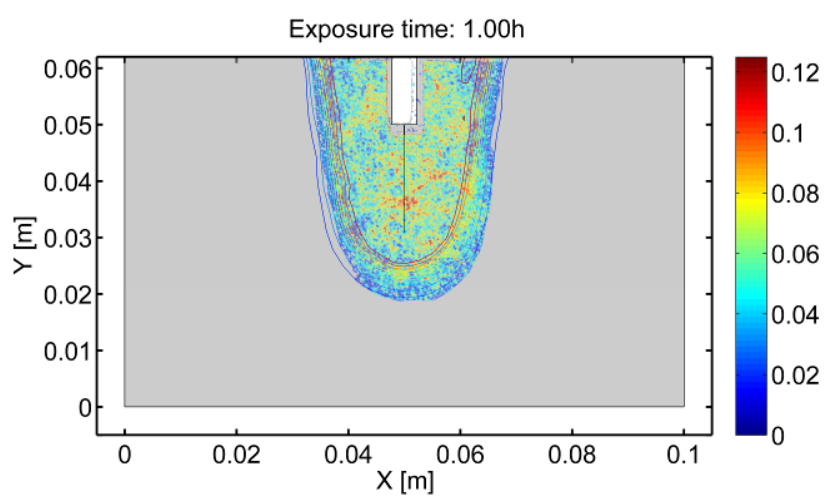

(b)

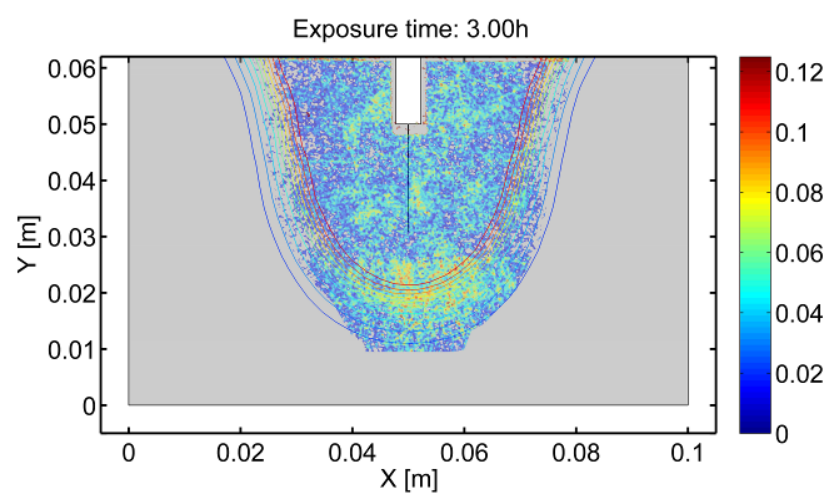

(d)

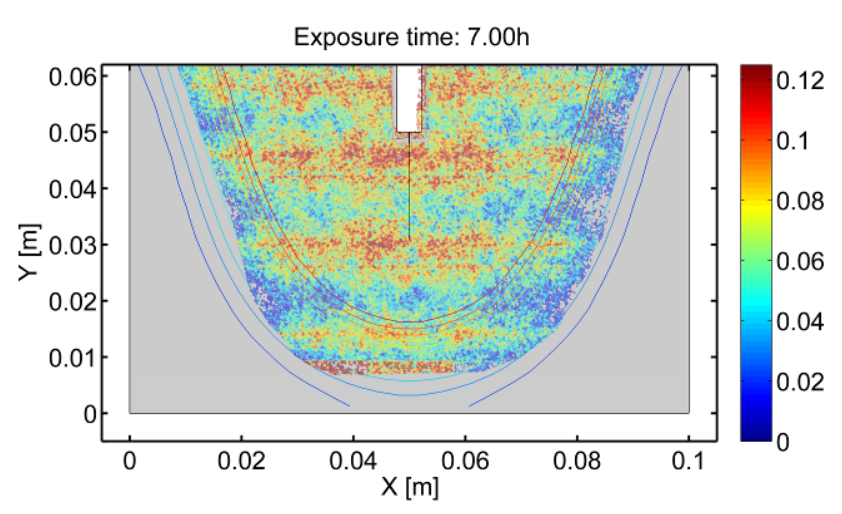

(f)

Figure 13: Experimental and modelled ingress results for $0.15 \mathrm{~mm}$ CMOD WST specimen after various hours of exposure to liquid water. Please note: color bar indicates (measured and modelled) moisture content in $\mathrm{m}^{3} / \mathrm{m}^{3}$. 


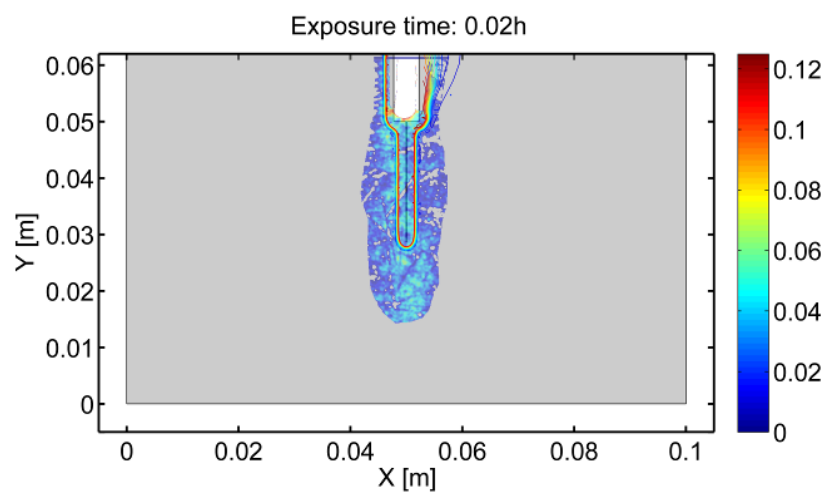

(a)

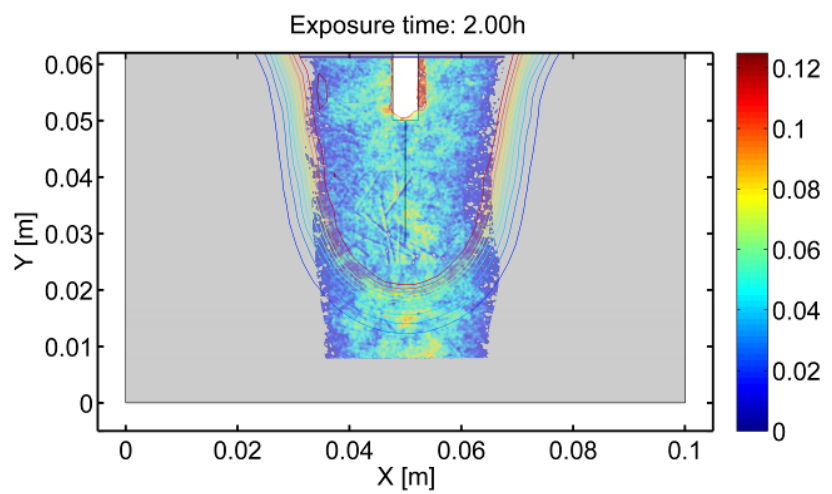

(c)

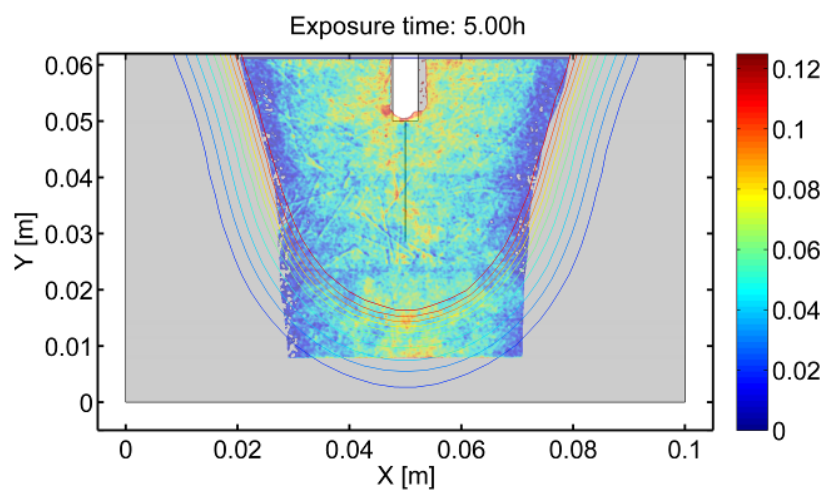

(e)

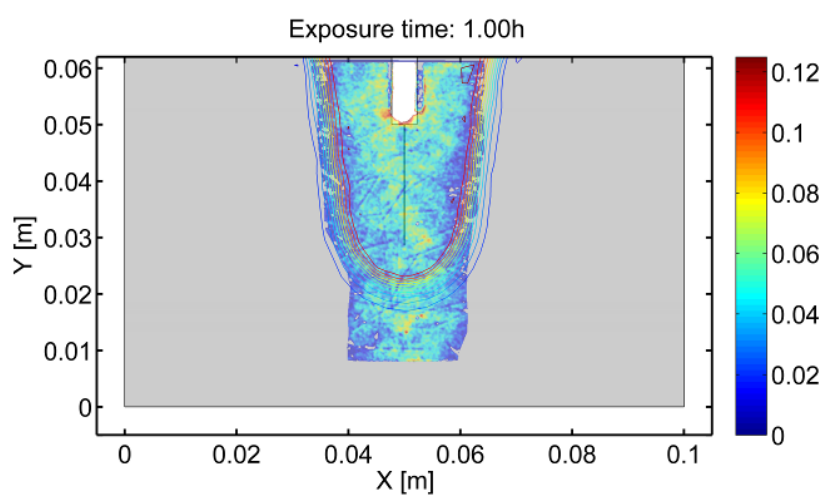

(b)

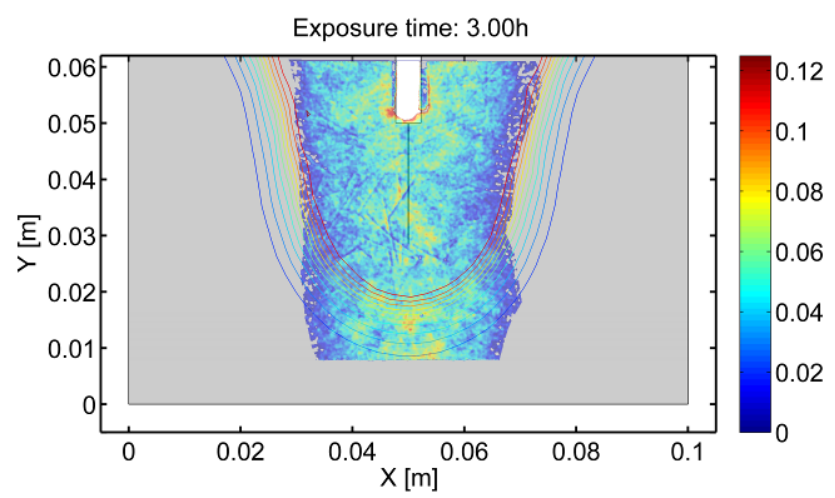

(d)

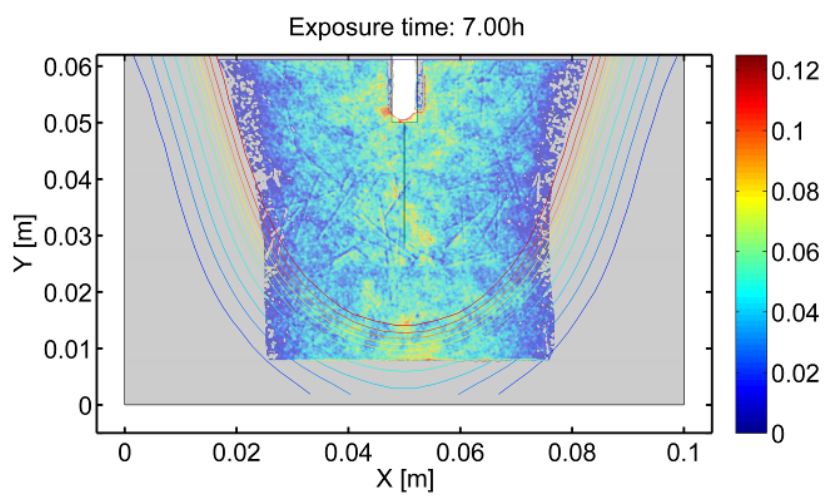

(f)

Figure 14: Experimental and modelled ingress results for $0.20 \mathrm{~mm}$ CMOD WST specimen after various hours of exposure to liquid water. Please note: color bar indicates (measured and modelled) moisture content in $\mathrm{m}^{3} / \mathrm{m}^{3}$. 


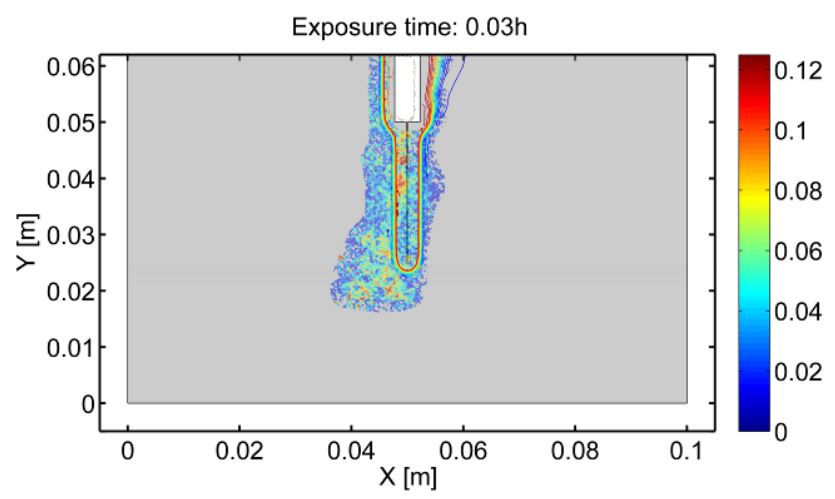

(a)

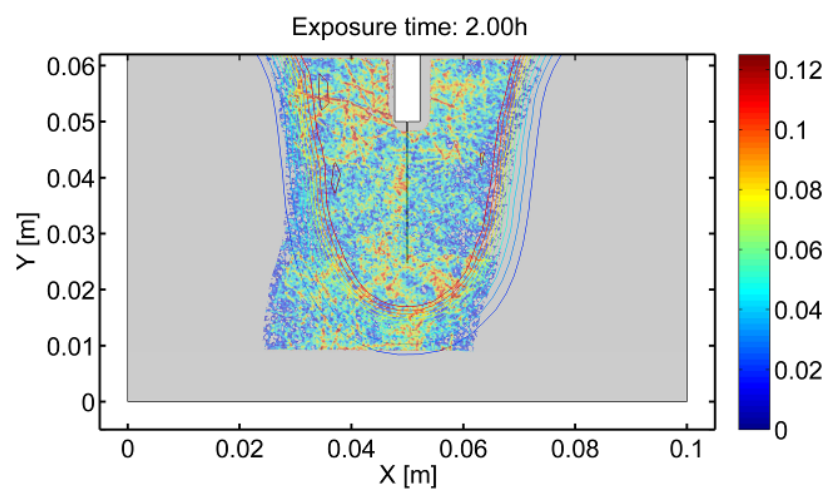

(c)

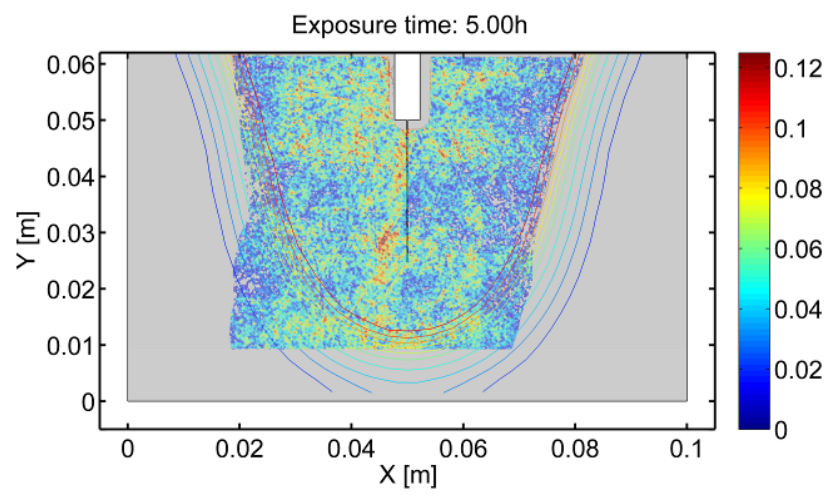

(e)

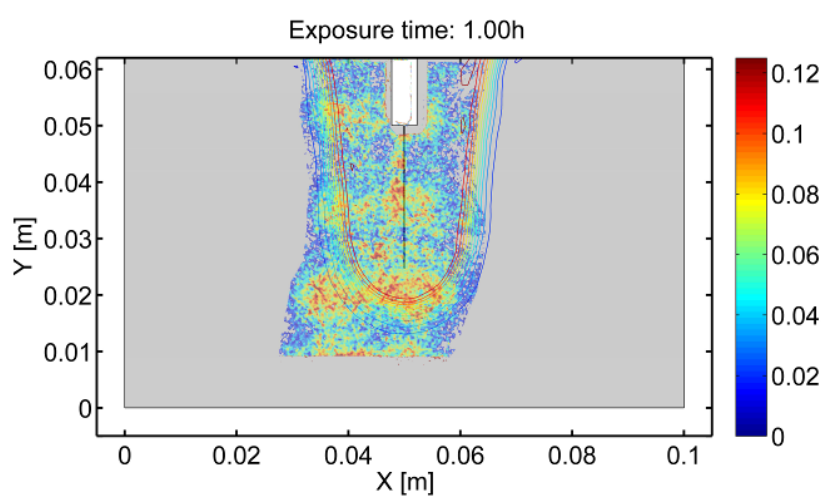

(b)

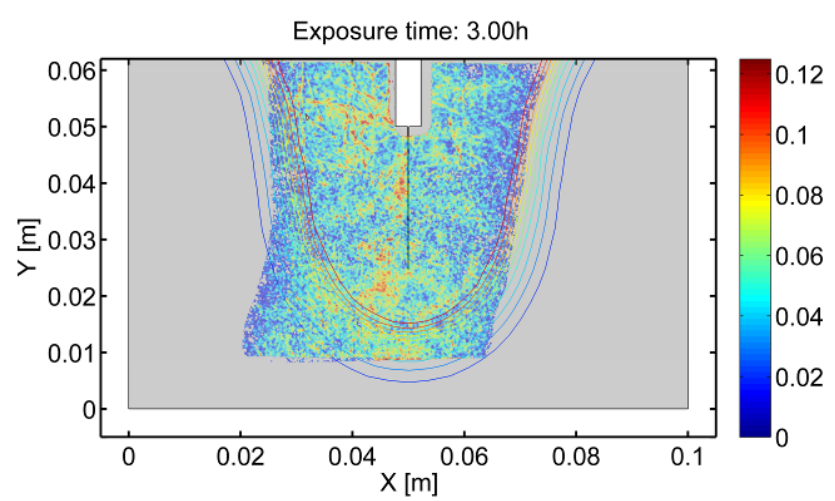

(d)

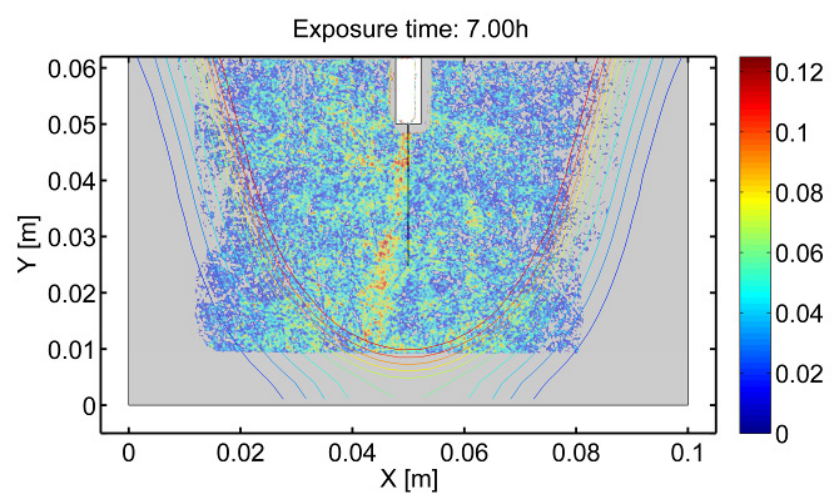

(f)

Figure 15: Experimental and modelled ingress results for $0.40 \mathrm{~mm}$ CMOD WST specimen after various hours of exposure to liquid water. Please note: color bar indicates (measured and modelled) moisture content in $\mathrm{m}^{3} / \mathrm{m}^{3}$. 


\section{Discussion}

While the results presented in Figs. 9 to 15 show that the moisture ingress front is clearly detected by the x-ray attenuation measurement technique, determination of the moisture content by means of this measurement technique is subjected to larger variability. The theoretical ability of the x-ray attenuation equipment used in this investigation to resolve changes in moisture content (i.e. change in moisture content required to attenuate a single x-ray photon) is discussed in [23]. Utilizing the equations provided in [23] with the combination of energy settings and specimen thickness utilized, it is possible to estimate a measurement resolution of approximately $1.7 \mathrm{~kg} / \mathrm{m}^{3}$ of water in the specimen. This measurement resolution is roughly two orders of magnitude less than the maximum water content in Figs. 9 to 15, and should be sufficient to avoid the type of fluctuation seen in Figure 11 (c). The phenomena observed may be related to varying intensity of the x-ray beam during a single measurement, which was not recorded in this investigation, and thus, hampers a more reliable determination of the water content in the test specimens. Although additional work and refinement in the measurement approach is needed to provide more precise and reliable quantifications of changes in moisture content, results allow for discussion of the extent of moisture ingress and the effects of cracks. Finally, it is noted that results are discussed in the following neglecting the influence of self-healing on the moisture ingress, see e.g. [15], due to the short-term nature of the experiments.

Comparison of results presented in Figs. 9 to 15 indicates moisture advances further over time within the test specimens and typically, attenuation measurements taken after 24 hours indicated the moisture front had moved beyond the measured area. The impact of the load level or CMOD is also apparent from the presented x-ray attenuation measurements, particularly in WST specimens that were loaded to peak load or cracked, respectively. Moisture ingress occurs more rapidly in the y-direction (vertical direction) of peak load and cracked WST specimens compared to specimens with $70 \%$ and $90 \%$ of peak load. The minimum moisture contour reaches depths of approximately $10 \mathrm{~mm}$ (peak load), $17 \mathrm{~mm}$ (0.10 mm CMOD), $25 \mathrm{~mm}$ (0.15 mm CMOD), $35 \mathrm{~mm}$ (0.20 mm CMOD), and $35 \mathrm{~mm}$ (0.40 mm CMOD) below the notch, respectively compared to approximately $7 \mathrm{~mm}$ below the notch for the $70 \%$ peak load specimen after less than ten minutes of exposure to liquid (see Figure 16 (a) and Figs. 9 to 15 (a)). The trend continues at later times, e.g., after five hours (see Figure 16 (e) and Figs. 9 to 15 (e)) of exposure, moisture reached approximately $30 \mathrm{~mm}$ below the notch for the peak load specimen, $40 \mathrm{~mm}$ for the $0.1 \mathrm{~mm}$ CMOD specimen, and $>40 \mathrm{~mm}$ for WST specimens with a CMOD larger than 0.10 $\mathrm{mm}$. Lateral ingress, however, appears to be unaffected by loading/cracking of the WST specimens, e.g., after one hour of exposure (Figure 16 (b) and Figs. 9 to 15 (b)) x-ray attenuation measurements indicate the lateral ingress reached a maximum of approximately $\pm 15-18 \mathrm{~mm}$ from the notch center for all specimens.

The experimental results were thereby satisfactorily reproduced by the numerical model described in Section 3 along with assumptions of a simplified crack geometry. In particular, division of the crack in a non-coalesced crack region with behavior similar to bulk concrete and a coalesced crack region, which behaved as a free surface for moisture ingress, led to very good agreements between experimental data and numerical predictions. The assumption of a constant length, i.e. $18.5 \mathrm{~mm}$ from the crack tip estimated by means of the CHM (see Section 4.1), for the non-coalesced crack region appears to hold true for all loading and cracking conditions investigated. This is reflected through the very good agreement between experimental data and numerical predictions concerning the vertical extent of moisture ingress. However, for larger CMODs, i.e., 0.20 and $0.40 \mathrm{~mm}$, respectively, the 
model did not accurately reflect the vertical extent of moisture ingress as measured from experiments. This difference was likely due to the crack in the WST specimen becoming unstable under the relatively high CMOD situations, possibly leading to a crack the penetrated the entire height of the WST specimen.

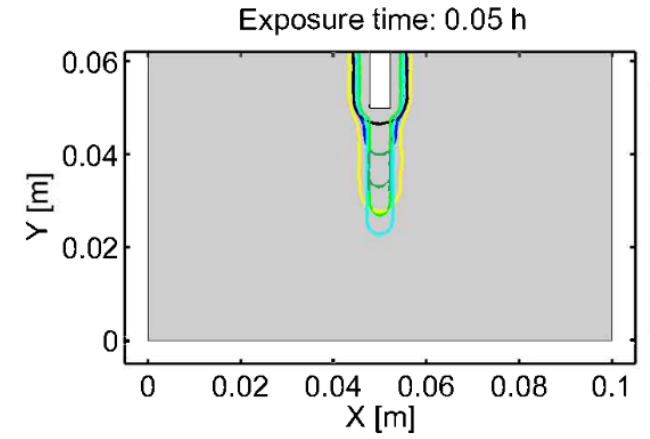

(a)

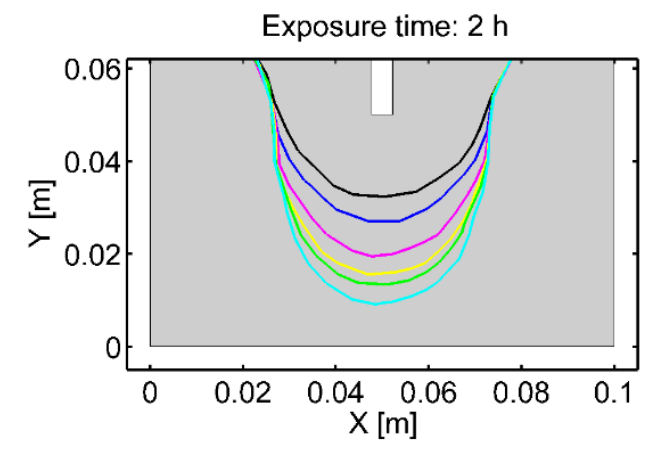

(c)

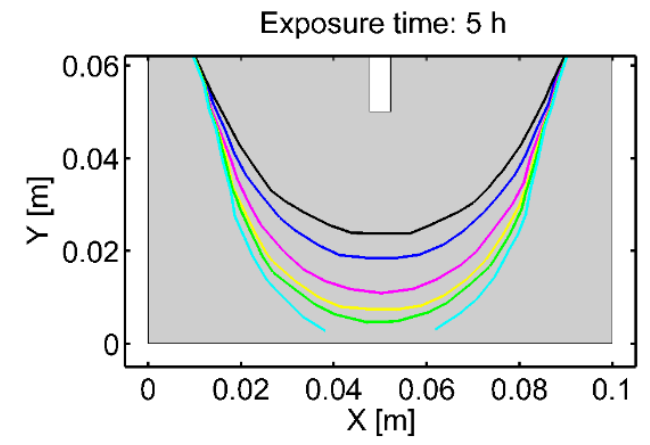

(e)

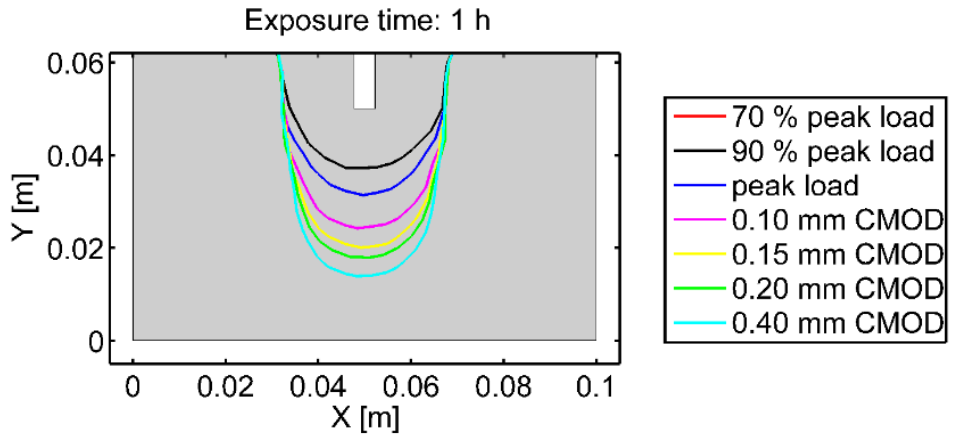

(b)

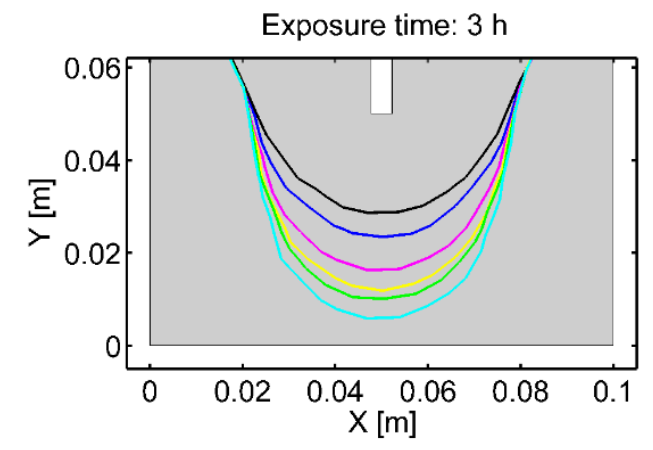

(d)

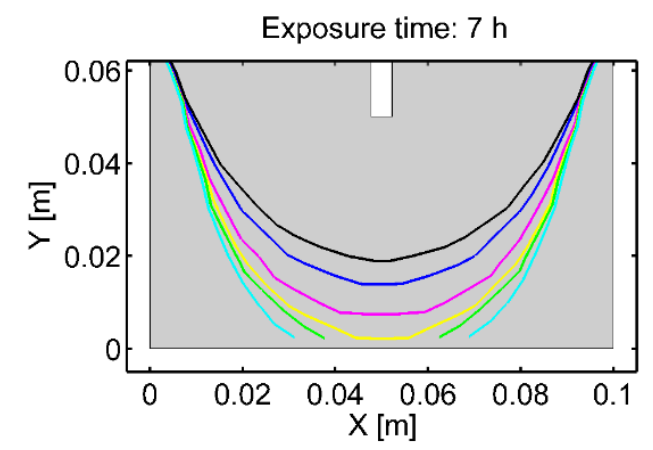

\begin{tabular}{|l|}
\hline$-70 \%$ peak load \\
$-90 \%$ peak load \\
- peak load \\
$-0.10 \mathrm{~mm}$ CMOD \\
$0.15 \mathrm{~mm} \mathrm{CMOD}$ \\
$-0.20 \mathrm{~mm} \mathrm{CMOD}$ \\
$-0.40 \mathrm{~mm} \mathrm{CMOD}$ \\
\hline
\end{tabular}

(f)

Figure 16: Numerical predictions of extend of moisture ingress for loaded/cracked WST specimens at selected times after exposure to liquid water.

\section{Conclusions}

Wedge split test (WST) specimens were conditioned to a relative humidity of $50 \%$, deformed to various states $(70 \%$ and $90 \%$ of peak load, peak load, and crack mouth opening displacement (CMOD's) of $0.10,0.15,0.20$, and $0.40 \mathrm{~mm}$ ) to induce damage and cracks, and exposed to liquid water. 
Comparison of moisture ingress fronts measured, by means of x-ray attenuation measurements, and modeled, using a liquid conductivity approach, concluded the following:

- The influence of cracks on the extent of moisture ingress was satisfactorily modelled using a simplified crack geometry in most cases. The simplified crack geometry consisted of a coalesced crack length, which behaves as a free surface for moisture ingress, and a portion of the crack, which resists moisture ingress similarly to the bulk material, likely consisting of isolated micro cracks.

- The extent of ingress into the depth increased with increasing crack deformation at a given time; however, the extent of lateral ingress at a given time remained relatively constant for all load/crack states.

- (Reinforced) concrete has a varying moisture storage capacity due to natural variations in cement content. The presented model assumes a homogeneous moisture storage capacity and therefore is unable to account for such variations.

- For WST specimen with larger CMODs (i.e., 0.20 and $0.40 \mathrm{~mm}$ ), the measured and modeled vertical extent of moisture ingress was found to be in disagreement, with the model underestimating its extent. It is hypothesized that the crack in the physical WST specimens became unstable with the larger CMODs, resulting in cracks penetrating the full specimen depth, and ultimately a more rapid penetration of water into the specimen depth.

In addition, this paper presents some fundamental observations and findings on the $\mathrm{x}$-ray attenuation measurement technique, as summarized here:

- A measurement normalization approach is presented that was found to mitigate the problematic variability between individual measurement locations in the x-ray attenuation measurements. The approach combines a local and global normalization of measurements, thus, improving the final quality of the measurements and allowing for a more precise determination of the location of the moisture front. Further improvements may still be realized as some unexpected fluctuations in the moisture contents were still observed when applying the presented normalization to x-ray attenuation measurements.

\section{Acknowledgements}

Experimental results presented herein were collected during the second author's Ph.D. work and therefore the guidance and support of his lead supervisor, Mette Geiker and co-supervisors, Henrik Stang and Jason Weiss is gratefully acknowledged. 


\section{References}

[1] A. Michel, P. V. Nygaard, M.R. Geiker, Experimental investigation on the short-term impact of temperature and moisture on reinforcement corrosion, Corros. Sci. 72 (2013) 26-34. doi:10.1016/j.corsci.2013.02.006.

[2] S. Poyet, A. Sellier, B. Capra, G. Thèvenin-Foray, J.-M. Torrenti, H. Tournier-Cognon, E. Bourdarot, Influence of Water on Alkali-Silica Reaction: Experimental Study and Numerical Simulations, J. Mater. Civ. Eng. 18 (2006) 588-596. doi:10.1061/(ASCE)0899-1561(2006)18:4(588).

[3] M.O. Mmusi, M.G. Alexander, H.D. Beushausen, Determination of critical moisture content for carbonation of concrete, in: M.G. Alexander, H.D. Beushausen (Eds.), Concr. Repair, Rehabil. Retrofit. II, CRC Press, 2009: p. 457. http://findit.dtu.dk/en/catalog/2359375089.

[4] W. Li, M. Pour-Ghaz, J. Castro, J. Weiss, Water Absorption and Critical Degree of Saturation Relating to FreezeThaw Damage in Concrete Pavement Joints, J. Mater. Civ. Eng. 24 (2012) 299-307. doi:10.1061/(ASCE)MT.19435533.0000383 .

[5] A. Voss, M. Pour-Ghaz, M. Vauhkonen, A. Seppänen, Electrical capacitance tomography to monitor unsaturated moisture ingress in cement-based materials, Cem. Concr. Res. 89 (2016) 158-167. doi:10.1016/j.cemconres.2016.07.011.

[6] M. Hallaji, A. Seppänen, M. Pour-Ghaz, Electrical resistance tomography to monitor unsaturated moisture flow in cementitious materials, Cem. Concr. Res. 69 (2015) 10-18. doi:10.1016/j.cemconres.2014.11.007.

[7] Z. Zhang, M. Thiery, V. Baroghel-Bouny, Investigation of moisture transport properties of cementitious materials, Cem. Concr. Res. 89 (2016) 257-268. doi:10.1016/j.cemconres.2016.08.013.

[8] M. Saeidpour, L. Wadsö, Moisture diffusion coefficients of mortars in absorption and desorption, Cem. Concr. Res. 83 (2016) 179-187. doi:10.1016/j.cemconres.2016.02.003.

[9] G.W. Scherer, J.J. Valenza, G. Simmons, New methods to measure liquid permeability in porous materials, Cem. Concr. Res. 37 (2007) 386-397. doi:10.1016/j.cemconres.2006.09.020.

[10] N.S. Martys, C.F. Ferraris, Capillary transport in mortars and concrete, Cem. Concr. Res. 27 (1997) 747-760. doi:10.1016/S0008-8846(97)00052-5.

[11] B. Šavija, M. Luković, E. Schlangen, Influence of Cracking on Moisture Uptake in Strain-Hardening Cementitious Composites, J. Nanomechanics Micromechanics. 7 (2017) 04016010. doi:10.1061/(ASCE)NM.2153-5477.0000114.

[12] B. Van Belleghem, R. Montoya, J. Dewanckele, N. Van den Steen, I. De Graeve, J. Deconinck, V. Cnudde, K. Van Tittelboom, N. De Belie, Capillary water absorption in cracked and uncracked mortar - A comparison between experimental study and finite element analysis, Constr. Build. Mater. 110 (2016) 154-162. doi:10.1016/j.conbuildmat.2016.02.027.

[13] P. Zhang, P. Wang, D. Hou, Z. Liu, M. Haist, T. Zhao, Application of neutron radiography in observing and quantifying the time-dependent moisture distributions in multi-cracked cement-based composites, Cem. Concr. Compos. 78 (2017) 13-20. doi:10.1016/j.cemconcomp.2016.12.006.

[14] C. Aldea, S.P. Shah, A. Karr, Permeability of cracked concrete, Mater. Struct. 32 (1999) 370-376.

[15] C. Edvardsen, Water permeability and autogenous healing of cracks in concrete, Aci Mater. J. 96 (1999) 448-454.

[16] B.J. Pease, J. Couch, M.R. Geiker, H. Stang, J. Weiss, Assessing the Portion of the Crack Length Contributing to Water Sorption in Concrete Using X-ray Absorption, Concr. Second Int. RILEM Work. Concr. Durab. Serv. Life Plan. (2009) 1-8.

[17] J. Weiss, J. Couch, B. Pease, P. Laugesen, M. Geiker, Influence of Mechanically Induced Cracking on Chloride Ingress in Concrete, J. Mater. Civ. Eng. 29 (2017) 04017128. doi:10.1061/(ASCE)MT.1943-5533.0001922.

[18] A. Hillerborg, M. Modéer, P.-E. Petersson, Analysis of crack formation and crack growth in concrete by means of 
fracture mechanics and finite elements, Cem. Concr. Res. 6 (1976) 773-781. doi:10.1016/0008-8846(76)90007-7.

[19] Beton - Materialer - Regler for anvendelse af EN 206-1 i Danmark, (2011).

http://findit.dtu.dk/en/catalog/2349365491 (accessed July 11, 2017).

[20] K.K. Hansen, S.K. Jensen, L. Gerward, K. Singh, K. K. Hansen, S. K. Jensen, L. Gerward, K. Singh, Dual-energy X-ray absorptiometry for the simultaneous determination of density and moisture content in porous structural materials, in: 5th Symp. Build. Phys. Nord. Ctries., Chalmers tekniska högskola, 1999: pp. 281-288.

[21] B.J. Pease, Influence of concrete cracking on ingress and reinforcement corrosion, Ph.D. Thesis, Technical University of Denmark, 2010.

[22] S. Roels, J. Carmeliet, Analysis of moisture flow in porous materials using microfocus X-ray radiography, Int. J. Heat Mass Transf. 49 (2006) 4762-4772. doi:10.1016/j.ijheatmasstransfer.2006.06.035.

[23] B.J. Pease, G.A. Scheffler, H. Janssen, Monitoring moisture movements in building materials using X-ray attenuation: Influence of beam-hardening of polychromatic X-ray photon beams, Constr. Build. Mater. 36 (2012) 419-429. doi:10.1016/j.conbuildmat.2012.04.126.

[24] A. Michel, B.J. Pease, M.R. Geiker, H. Stang, J.F. Olesen, Monitoring reinforcement corrosion and corrosioninduced cracking using non-destructive x-ray attenuation measurements, Cem. Concr. Res. 41 (2011) 1085-1094. doi:10.1016/j.cemconres.2011.06.006.

[25] J.P. Ulfkjær, S. Krenk, R. Brincker, Analytical Model for Fictitious Crack Propagation in Concrete Beams, J. Eng. Mech. 121 (1995) 7-15. doi:10.1061/(ASCE)0733-9399(1995)121:1(7).

[26] J.F. Olesen, Fictitious crack propagation in fiber-reinforced concrete beams, J. Eng. Mech. 127 (2001) 272-280. doi:10.1061/(ASCE)0733-9399(2001)127:3(272).

[27] L. Østergaard, H. Stang, J.F. Olesen, Interpretation and inverse analysis of the wedge splitting test, in: A. Neimitz (Ed.), Fract. Mech. Beyond 2000, 2000: pp. 593-600.

[28] J. Skoček, H. Stang, Inverse analysis of the wedge-splitting test, Eng. Fract. Mech. 75 (2008) 3173-3188. doi:10.1016/j.engfracmech.2007.12.003.

[29] B.J. Pease, A. Michel, M.R. Geiker, H. Stang, Modeling moisture ingress through simplified concrete crack geometries, in: H. Justnes (Ed.), ICDC 2012, Int. Congr. Durab. Concr., Norsk Betongforening by Norwegian Concrete Association, Trondheim, 2011.

[30] H. Janssen, B. Blocken, J. Carmeliet, Conservative modelling of the moisture and heat transfer in building components under atmospheric excitation, Int. J. Heat Mass Transf. 50 (2007) 1128-1140. doi:10.1016/j.ijheatmasstransfer.2006.06.048.

[31] J.R. Philip, D.A. De Vries, Moisture movement in porous materials under temperature gradients, Trans. Am. Geophys. Union. 38 (1957) 222. doi:10.1029/TR038i002p00222.

[32] F.A.L. Dullien, Porous media : fluid transport and pore structure, Academic Press, 1979.

[33] J. Bear, Y. Bachmat, Introduction to modeling of transport phenomena in porous media, Kluwer Academic Publishers, 1991.

[34] J. Carmeliet, S. Roels, Determination of the Moisture Capacity of Porous Building Materials, J. Build. Phys. 25 (2002) 209-237. doi:10.1106/109719602022835.

[35] R. Schirmer, Die Diffusionszahl von Wasserdampf-Luft-Gemischen und die Verdampfungsgeschwindigkeit, VDIVerlag, 1938.

[36] G.A. Scheffler, R. Plagge, A whole range hygric material model: Modelling liquid and vapour transport properties in porous media, Int. J. Heat Mass Transf. 53 (2010) 286-296. doi:10.1016/j.ijheatmasstransfer.2009.09.030.

[37] Y. Mualem, A new model for predicting the hydraulic conductivity of unsaturated porous media, Water Resour. 
Res. 12 (1976) 513-522. doi:10.1029/WR012i003p00513.

[38] G. Scheffler, Validation of Hygrothermal Material Modelling Under Consideration of the Hysteresis of Moisture Storage, Ph.D. Thesis, TU Dresden, 2008.

[39] M. Pour-Ghaz, F. Rajabipour, J. Couch, J. Weiss, Numerical and experimental assessment of unsaturated fluid transport in saw-cut (Notched) concrete elements, Am. Concr. Institute, ACI Spec. Publ. (2009) 73-85.

[40] H. Derluyn, H. Janssen, J. Carmeliet, Influence of the nature of interfaces on the capillary transport in layered materials, Constr. Build. Mater. 25 (2011) 3685-3693. doi:10.1016/j.conbuildmat.2011.03.063.

[41] H.-W. Song, S.-W. Pack, S.-H. Nam, J.-C. Jang, V. Saraswathy, Estimation of the permeability of silica fume cement concrete, Constr. Build. Mater. 24 (2010) 315-321. doi:10.1016/j.conbuildmat.2009.08.033. 